NASA / TM-1999-209365

ARL-TR-2012
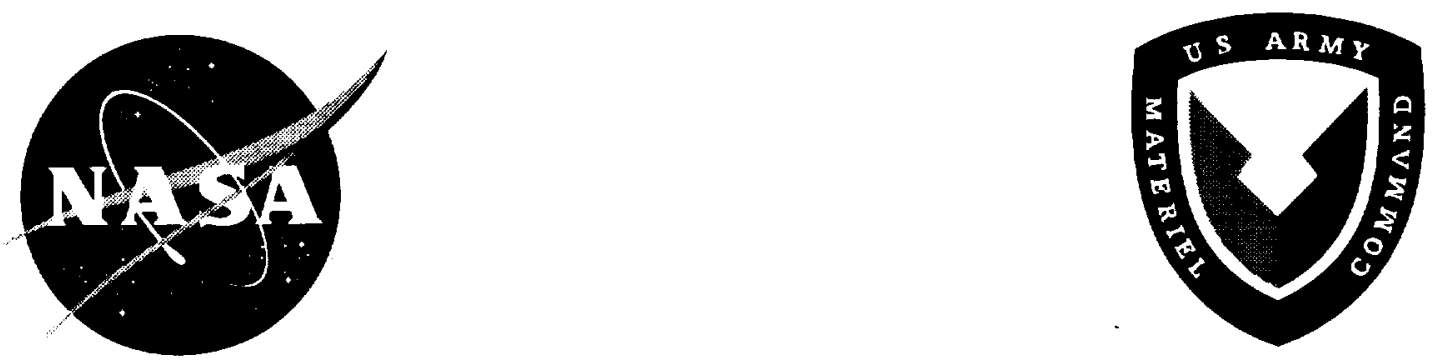

\title{
A Method for Calculating Strain Energy Release Rates in Preliminary Design of Composite Skin/Stringer Debonding Under Multi-Axial Loading
}

Ronald Krueger

National Research Council

Langley Research Center, Hampton, Virginia

Pierre J. Minguet

The Boeing Company, Philadelphia, Pennsylvania

T. Kevin O'Brien

U.S. Army Research Laboratory

Vehicle Technology Directorate

Langley Research Center, Hampton, Virginia 


\section{The NASA STI Program Office ... in Profile}

Since its founding, NASA has been dedicated to the advancement of aeronautics and space science. The NASA Scientific and Technical Information (STI) Program Office plays a key part in helping NASA maintain this important role.

The NASA STI Program Office is operated by Langley Research Center, the lead center for NASA's scientific and technical information. The NASA STI Program Office provides access to the NASA STI Database, the largest collection of aeronautical and space science STI in the world. The Program Office is also NASA's institutional mechanism for disseminating the results of its research and development activities. These results are published by NASA in the NASA STI Report Series, which includes the following report types:

- TECHNICAL PUBLICATION. Reports of completed research or a major significant phase of research that present the results of NASA programs and include extensive data or theoretical analysis. Includes compilations of significant scientific and technical data and information deemed to be of continuing reference value. NASA counterpart of peer-reviewed formal professional papers, but having less stringent limitations on manuscript length and extent of graphic presentations.

- TECHNICAL MEMORANDUM. Scientific and technical findings that are preliminary or of specialized interest, e.g., quick release reports, working papers, and bibliographies that contain minimal annotation. Does not contain extensive analysis.

- CONTRACTOR REPORT. Scientific and technical findings by NASA-sponsored contractors and grantees.
- CONFERENCE PUBLICATION. Collected papers from scientific and technical conferences, symposia, seminars, or other meetings sponsored or co-sponsored by NASA.

- SPECIAL PUBLICATION. Scientific, technical, or historical information from NASA programs, projects, and missions, often concerned with subjects having substantial public interest.

- TECHNICAL TRANSLATION. Englishlanguage translations of foreign scientific and technical material pertinent to NASA's mission.

Specialized services that complement the STI Program Office's diverse offerings include creating custom thesauri, building customized databases, organizing and publishing research results ... even providing videos.

For more information about the NASA STI Program Office, see the following:

- Access the NASA STI Program Home Page at http://www.sti.nasa.gov

- E-mail your question via the Internet to help@sti.nasa.gov

- Fax your question to the NASA STI Help Desk at (301) 621-0134

- Phone the NASA STI Help Desk at (301) 621-0390

- Write to:

NASA STI Help Desk

NASA Center for AeroSpace Information 7121 Standard Drive Hanover, MD 21076-1320 
NASA / TM-1999-209365

ARL-TR-2012
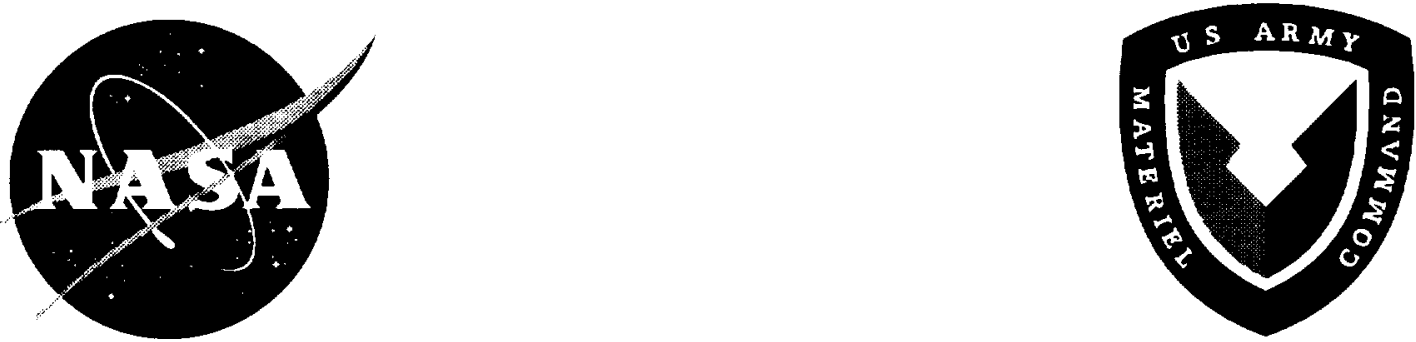

\section{A Method for Calculating Strain Energy Release Rates in Preliminary Design of Composite Skin/Stringer Debonding Under Multi-Axial Loading}

Ronald Krueger

National Research Council

Langley Research Center, Hampton, Virginia

Pierre J. Minguet

The Boeing Company, Philadelphia, Pennsylvania

T. Kevin O'Brien

U.S. Army Research Laboratory

Vehicle Technology Directorate

Langley Research Center, Hampton, Virginia

National Aeronautics and

Space Administration

Langley Research Center

Hampton, Virginia 23681-2199

July 1999 
The use of trademarks or names of manufacturers in the report is for accurate reporting and does not constitute an official endorsement, either expressed or implied, of such products or manufacturers by the National Aeronautics and Space Administration or the U.S. Army.

Available from:

NASA Center for AeroSpace Information (CASI) 7121 Standard Drive Hanover, MD 21076-1320

(301) $621-0390$
National Technical Information Service (NTIS) 5285 Port Royal Road

Springfield, VA 22161-2171

(703) 605-6000 


\title{
A METHOD FOR CALCULATING STRAIN ENERGY RELEASE RATES IN PRELIMINARY DESIGN OF COMPOSITE SKIN/STRINGER DEBONDING UNDER MULTI-AXIAL LOADING
}

\author{
Ronald Krueger ${ }^{1}$, Pierre J. Minguet ${ }^{3}$, and T. Kevin O'Brien ${ }^{2}$ \\ ${ }^{1}$ National Research Council Research Associate \\ ${ }^{2}$ U.S. Army Research Laboratory, Vehicle Technology Directorate \\ NASA Langley Research Center \\ Hampton, VA 23681 \\ ${ }^{3}$ Boeing \\ Philadelphia, PA 19142
}

\section{ABSTRACT}

Three simple procedures were developed to determine strain energy release rates, $G$, in composite skin/stringer specimens for various combinations of uniaxial and biaxial (in-plane/out-of-plane) loading conditions. These procedures may be used for parametric design studies in such a way that only a few finite element computations will be necessary for a study of many load combinations. The results were compared with mixed mode strain energy release rates calculated directly from nonlinear two-dimensional plane-strain finite element analyses using the virtual crack closure technique. The first procedure involved solving three unknown parameters needed to determine the energy release rates. Good agreement was obtained when the external loads were used in the expression derived. This superposition technique, however, was only applicable if the structure exhibits a linear load/deflection behavior. Consequently, a second modified technique was derived which was applicable in the case of nonlinear load/deformation behavior. The technique, however, involved calculating six unknown parameters from a set of six simultaneous linear equations with data from six nonlinear analyses to determine the energy release rates. This procedure was not time efficient, and hence, less appealing.

Finally, a third procedure was developed to calculate mixed mode energy release rates as a function of delamination lengths. This procedure required only one nonlinear finite element analysis of the specimen with a single delamination length to obtain a reference solution for the 
energy release rates and the scale factors. The delamination was subsequently extended in three separate linear models of the local area in the vicinity of the delamination subjected to unit loads to obtain the distribution of $G$ with delamination lengths. This set of sub-problems was solved using linear finite element analyses, which resulted in a considerable reduction in CPU time compared to a series of nonlinear analyses. Although additional modeling effort is required to create the local sub-model, this superposition technique is very efficient for large parametric studies, which may occur during preliminary design where multiple load combinations must be considered.

\section{KEY WORDS}

Composite materials, fracture mechanics, energy release rate, finite element analysis, virtual crack closure technique, skin/flange interface.

\section{INTRODUCTION}

Carbon epoxy composite structures are widely used by today's aircraft manufacturers to reduce weight. Many composite components in aerospace structures consist of flat or curved panels with co-cured or adhesively bonded frames and stiffeners. Testing of stiffened panels designed for pressurized aircraft fuselage has shown that bond failure at the tip of the frame flange is an important and very likely failure mode [1]. Comparatively simple simulation specimens consisting of a stringer bonded onto a skin were developed and it was shown in experiments that the failure initiated at the tip of the flange, identical to the failure observed in the full-size panels and frame pull-off specimens [2-7].

The overall objective of the current work is to develop a simple procedure to calculate the strain energy release rate for delaminations originating from matrix cracks in these skin/stringer simulation coupons for arbitrary load combinations. The total strain energy release rate would then be compared to critical values obtained from an existing mixed-mode failure criterion to predict delamination onset. This procedure could then be used for parametric design studies in such a way that only a few finite element computations would be necessary to evaluate bonded joint response due to many load combinations. Since energy is a quadratic function of the applied loads, simple superposition to add the energy release rates from separate load cases is not valid. Therefore, a simple quadratic expression is developed to calculate the strain energy release rate for any combination of loads [4]. To validate this approach, results obtained from the quadratic expression are compared to mode I and mode II strain energy release rate components, which are calculated from nonlinear two-dimensional plane-strain finite element analyses using the virtual crack closure 
technique $[8,9]$.

Three simple procedures are developed to determine strain energy release rates, $G$, in composite skin/stringer specimens for various combinations of uniaxial and biaxial (in-plane/out-of-plane) loading conditions. The first procedure involved solving three unknown parameters needed to determine the energy release rates. This superposition technique, however, was only applicable if the structure exhibits a linear load/deflection behavior. Consequently, a second modified technique is derived which is applicable in the case of nonlinear load/deformation behavior. A third procedure is developed to calculate mixed mode energy release rate as a function of delamination length. This procedure requires only one nonlinear finite element analysis of the specimen with a single delamination length to obtain a reference solution for the energy release rates and the scale factors.

\section{BACKGROUND}

Previous investigations of the failure of secondary bonded structures focused on loading conditions as typically experienced by aircraft crown fuselage panels. Tests were conducted with specimens cut from a full-size panel to verify the integrity of the bondline between the skin and the flange or frame [1]. However, these panels were rather expensive to produce and there is a need for a test configuration that would allow detailed observations of the failure mechanism at the skin/flange interface. A simpler specimen configuration was proposed in reference 2 . The investigations focused on the failure mechanisms of a bonded skin/flange coupon configuration loaded in bending [2-5]. In many cases, however, composite structures may experience both bending and membrane loads during in-flight service. Damage mechanisms in composite bonded skin/stringer structures under monotonic tension, three-point bending, and combined tension/bending loading conditions were investigated in references 6 and 7. An analytical methodology was also developed to predict the location and orientation of the first transverse matrix crack based on the principal transverse tension stress distribution in the off axis plies nearest the bondline in the vicinity of flange tip. The prediction of delamination onset was based on energy release rate calculations.

The specimens tested in references 6 and 7 consisted of a bonded skin and flange assembly as shown in Figure 1. Both the skin and the flange laminates had a multidirectional lay-up made from IM6/3501-6 graphite/epoxy prepreg tape with a nominal ply thickness of $h=0.188 \mathrm{~mm}$. The

skin lay-up, consisting of 14 plies, was [0/45/90/-45/45/-45/0] $]_{\mathrm{s}}$ and the flange lay-up, consisting of 10 plies, was [45/90/-45/0/90]s. The measured bondline thickness averaged $0.102 \mathrm{~mm}$. Specimens were 25.4-mm wide and 203.2-mm long. Typical material properties for the composite 
tape and the adhesive material used in the analysis were taken from reference 2 and are summarized in Table 1.

The specimens were subjected to pure tension, three-point bending, and combined axial tension and bending loads. A schematic of the deformed specimen geometries, the boundary conditions, and the loads corresponding to the first damage observed are shown in Figure 2 . In the combined axial tension and bending load case, a constant axial load, $P$, was applied in a first load step while transverse loads remained zero. In a second load step, the axial load was kept constant while the load orientation rotated with the specimen as it deformed under the transverse load. The tests were terminated when the flange debonded unstably from one of the flange tips. Damage was documented from photographs of the polished specimen edges at each of the four flange corners identified in Figure 3(a). Typical damage patterns, which were similar for all three loading configurations, are shown in Figure 3(b) and (c). Corners 1 and 4 and comers 2 and 3 had identical damage patterns. At corners 1 and 4, a delamination running in the $90^{\circ} / 45^{\circ}$ flange ply interface (delamination A) initiated from a matrix crack in the $90^{\circ}$ flange ply as shown in Figure 3(b). At longer delamination lengths, new matrix cracks formed and branched into both the $45^{\circ}$ ply below the delaminated interface as well as the $90^{\circ}$ flange ply above the interface. At corners 2 and 3 a matrix crack formed at the flange tip in the $90^{\circ}$ flange ply that subsequently ran through the lower $45^{\circ}$ flange ply and the bondline into the skin as shown in Figure 3(c). Subsequently, a split (delamination B1) formed from the tip of that matrix crack within the top $0^{\circ}$ skin ply and in some cases, a second delamination (delamination B2) was observed below the first in the top $0^{\circ} / 45^{\circ}$ skin ply interface.

In previous investigations, stress analyses were used to predict the location and orientation of the first transverse matrix crack based on the principal transverse tension stress distribution in the off axis plies nearest the bondline in the vicinity of the flange tip [6,7]. A comparison of the trajectories of the maximum principle tension stress with the damage patterns shown in Figures 3(b) and (c) indicated that the matrix crack starts to grow perpendicular to the trajectories. For all three loading conditions, maximum principal tensile stresses in the $90^{\circ}$ ply closest to the bondline, computed for applied loads at damage onset, were almost identical and exceeded the transverse tension strength of the material. Subsequent finite element analyses of delamination growth from these matrix cracks were performed using the virtual crack closure technique. However, because the specimen geometry and loadings required nonlinear analyses, this was a computationally intensive process. 


\section{ANALYSIS FORMULATION}

\section{FINITE ELEMENT MODEL}

In the current investigation the finite element $(\mathrm{FE})$ method was used to analyze the test specimens for each loading case. The goal of this analysis is to evaluate strain energy release rate components at the delamination tip using the virtual crack closure technique $[8,9]$. To develop a simple procedure to calculate the strain energy release for delaminations originating from matrix cracks, it was reasonable to focus only on one damage pattern during the investigation. Therefore, only a FE model of a specimen with a delamination running in the $90 \% 45^{\circ}$ flange ply interface, corresponding to Figure $3 \mathrm{~b}$, was developed and loads and boundary conditions were applied to simulate the three load cases. The two-dimensional cross section of the specimens was modeled

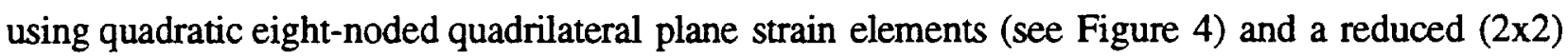
integration scheme was used for these elements. For the entire investigation, the ABAQUS finite element software was used [10].

An outline and two detailed views of the FE model are shown in Figure 4. A refined mesh was used in the critical area of the $90^{\circ}$ flange ply where matrix cracks and delaminations were observed in the test specimens. Outside the refined mesh area, all plies were modeled with one element through the ply thickness. Two elements were used per ply thickness in the refined region, except for the first three individual flange plies above the bondline and the skin ply below the bondline, which were modeled with four elements. Three elements through-the-thickness were used for the adhesive film. Based upon the experimental observations shown in Figure $3 \mathrm{~b}$, the model included a discrete matrix crack and a delamination. The initial matrix crack was modeled perpendicular to the flange taper, as suggested by the microscopic investigation as well as the stress analysis, which showed that the matrix crack starts to grow perpendicular to the trajectory of the maximum principle tension stress [6,7]. Damage was modeled at one flange tip as shown in Figure 4. The mesh used to model the undamaged specimen, as discussed in reference 6 and 7 , was employed at the opposite taper. The model consisted of 6977 elements and 21486 nodes and had 42931 degrees of freedom.

For the combined tension and bending load case, performed in NASA Langley's axial tension and bending test frame [11,12], the top grip, the load cell, and the load pin were modeled using three-noded quadratic beam elements as shown in Figures $2 c$ and 5 , to accurately simulate the combined tension and bending loads applied [6,7]. The beams were connected to the two-dimensional plane strain model of the specimen using multi-point constraints to enforce appropriate translations and rotations. As shown in Figure 5, nodes 1-29 along the edge of the plane strain model $(x=101.6 \mathrm{~mm}$ ) were constrained to move as a plane with the same rotation as beam node $\mathrm{A}$. To be consistent with the actual tests, a constant axial load, $P$, was applied in a first 
load step while transverse loads remained zero. In a second load step, the axial load was kept constant while the load orientation rotated with the specimen as it deformed under the transverse load. During the tests, the maximum specimen deflections under the transverse load were recorded at the top grip contact point. In the FE simulation a prescribed displacement, $v$, was applied which corresponded to the recorded transverse stroke. For the beam model of the steel parts (top grip, load cell, and load pin), a Young's Modulus of $210 \mathrm{GPa}$ and a Poisson's Ratio of 0.3 were used as material input data. A rectangular beam cross section was selected to model the square cross section of the top grip $\left(I=1.87 \times 10^{6} \mathrm{~mm}^{4}\right)$ and load pin $\left(I=1.4 \times 10^{6} \mathrm{~mm}^{4}\right)$ and a circular beam cross section was used to model the cylindrical load cell $\left(I=8.37 \times 10^{3} \mathrm{~mm}^{4}\right)$.

When applying two dimensional plane strain FE models it is assumed that the geometry, boundary conditions and other properties are constant across the entire width of the specimen. The current model, thus, may not always capture the true nature of the problem. As shown in Figure 3, the delamination pattern changed from corner 3 to corner 4 from a delamination running in the $90^{\circ} / 45^{\circ}$ interface to a delamination propagating between the adhesive film and the top $0^{\circ}$ ply of the skin. This is a three dimensional effect and can not be accounted for in the current plane strain model.

\section{VIRTUAL CRACK CLOSURE TECHNIQUE}

The Virtual Crack Closure Technique (VCCT) described in references 8 and 9 was used to calculate strain energy release rates for the delaminations. The mode I and mode II components of the strain energy release rate, $G_{\mathrm{I}}$ and $G_{\mathrm{I}}$, were calculated as (see Figure 6)

$$
G_{1}=-\frac{1}{2 \Delta a}\left[Y_{1}\left(v_{m}^{\prime}-v_{m}^{\prime}\right)+Y_{j}\left(v_{\ell}^{\prime}-v_{\ell}^{\prime}\right)\right]
$$

and

$$
G_{\| 1}=-\frac{1}{2 \Delta a}\left[X_{\mathrm{i}}\left(u_{\mathrm{m}}^{\prime}-u_{\mathrm{m}^{*}}^{*}\right)+X_{\mathrm{j}}\left(u_{\ell}^{\prime},-u_{\ell^{\prime}}\right)\right]
$$

where $\Delta a$ is the length of the elements at the delamination tip, $X_{i}^{\prime}$ and $Y_{i}^{\prime}$ are the forces at the delamination tip at node $\mathrm{i}$, and $u_{\mathrm{m}}{ }^{\prime}$ and $\nu_{\mathrm{m}}{ }^{\prime}$ are the relative displacements at the corresponding node $\mathrm{m}$ behind the delamination tip as shown in Figure 6. Similar definitions are applicable for the forces at node $\mathrm{j}$ and displacements at node $\ell$. For geometrically nonlinear analysis, both forces and displacements were transformed into a local coordinate system $\left(x^{\prime}, y^{\prime}\right)$, that defined the normal and tangential coordinate directions at the delamination tip in the deformed configuration. The mode III component is identically zero for the plane strain case. Therefore, the total strain energy release 
rate, $G_{\mathrm{T}}$, was obtained by summing the individual mode components as

$$
G_{\mathrm{T}}=G_{\mathrm{I}}+G_{\mathrm{II}} \text {. }
$$

The data required to perform the VCCT in equations (1) to (3) were accessed directly from the ABAQUS binary result file to get better accuracy. The calculations were performed in a separate post processing step using nodal displacements and nodal forces at the local elements in the vicinity of the delamination front.

Care must be exercised in interpreting the values for $G_{\mathrm{I}}$ and $G_{\mathrm{II}}$ obtained using the virtual crack closure technique for interfacial delaminations between two orthotropic solids [13,14]. For the current investigation, the element length $\Delta a$ was chosen to be about $1 / 4$ of the ply thickness, $h$, for the delamination in the $90^{\circ} / 45^{\circ}$ flange ply interface. Note that for the FE model shown in Figure $4 \Delta a h=0.181$ for the element behind and $\Delta a h=0.25$ for the element in front of the delamination tip. Therefore, the technique suggested in reference 8 was used to estimate the forces $X_{i}{ }^{\prime}$ and $Y_{i}^{\prime}$ for the case of unequal element lengths at the delamination tip. For the further delamination growth a value of $\Delta a / h=0.25$ was used.

\section{ANALYTICAL INVESTIGATION}

\section{SUPERPOSITION TECHNIQUE FOR LINEAR DEFORMATION BEHAVIOR}

The schematics of the specimen, boundary conditions, and three load cases (tension, bending and combined tension and bending) considered in this part of the study are shown in Figure 7. These boundary conditions and loads, however, do not represent the conditions applied during the experiments as given in Figure 2 of the previous section. This new set of boundary conditions was chosen to simplify the derivation of the superposition technique for linear deformation behavior. It was postulated that the specimen exhibits a linear load deflection behavior for the three load cases shown. Only linear finite element analyses were used. The boundary conditions applied were the same for all load cases.

For a specimen subjected to a pure tension load $P$ as shown in Figure 7(a), the energy release rate $G_{P}$ at the delamination tip can be calculated as

$$
G_{P}=\frac{P^{2}}{2} \cdot \frac{\partial C_{P}}{\partial A}
$$

where $C_{P}$ is the compliance of the specimen and $\partial A$ is the increase in surface area corresponding to an incremental increase in load or displacement at fracture [15]. For a specimen subjected to a bending load $Q$, as shown in Figure 7(b), the energy release rate $G_{Q}$ at the delamination tip can be 
calculated accordingly as

$$
G_{Q}=\frac{Q^{2}}{2} \cdot \frac{\partial C_{Q}}{\partial A} .
$$

If the external load, $R$, applied in the linear analysis is simply a fraction or multiple of the tension load $P, R=n P$, or the bending load $Q, R=m Q$, the energy release rate $G_{R}$ for the new load case may be obtained from the known values using

$$
G_{R}=n^{2} G_{P} \quad \text { or } \quad G_{R}=m^{2} G_{Q} .
$$

In the case of a combined tension/bending load case as shown in Figure 7(c), where the external load is a combination of a fraction or multiple $n$ of the tension load $P$ and a different fraction or multiple $m$ of the bending load $Q, R=n P+m Q$, we obtain

$$
G_{R}=\frac{(n P+m Q)^{2}}{2} \cdot \frac{\partial C_{R}}{\partial A}=\frac{\left(n^{2} P^{2}+2 m n P Q+m^{2} Q^{2}\right)}{2} \cdot \frac{\partial C_{R}}{\partial A} .
$$

Note that for a tension load, $P$, only, $\frac{\partial C_{R}}{\partial A}=\frac{\partial C_{P}}{\partial A}$ and for a bending load, $Q$, only, $\frac{\partial C_{R}}{\partial A}=\frac{\partial C_{Q}}{\partial A}$. For the combined load case equation (7) can then be approximated by

$$
G_{R} \cong \frac{n^{2} P^{2}}{2} \cdot \frac{\partial C_{P}}{\partial A}+2 m n \frac{P Q}{2} \frac{\partial C_{R}}{\partial A}+\frac{m^{2} Q^{2}}{2} \cdot \frac{\partial C_{Q}}{\partial A},
$$

Using equations (4) and (5) yields

$$
G_{R} \cong n^{2} G_{P}+2 m n \cdot \underbrace{\frac{P Q}{2} \cdot \frac{\partial C_{R}}{\partial A}}_{G_{P Q}}+m^{2} G_{Q},
$$

where $G_{P Q}$ is a coupling term which has the dimension of an energy release rate.

First, linear FE analyses of a simple tension and simple bending case are performed using VCCT to determine $G_{\eta}, G_{I I}$ and $G_{T}$. This allows calculation of the $G_{P}$ and $G_{Q}$ parameters in equation (9) for total $G$, and the $G_{I}$ and $G_{n}$ components. Then a single linear FE analysis of a combined tension and bending load case is performed using VCCT to obtain the $G_{R}$ parameter in equation (9) for $G_{l}, G_{I I}$ and $G_{T}$. Once these parameters are determined, then $G_{P Q}$ may be calculated for $G_{l}, G_{I I}$ and $G_{T}$. The parameters $G_{p}, G_{Q}$ and $G_{P Q}$ may now be used to calculate $G_{R}$ for $G_{I} G_{I I}$ and $G_{T}$ for other tension and bending load combinations.

Mode I and mode II values were computed using VCCT for a delamination running in the $90^{\circ} / 45^{\circ}$ flange ply interface with a length equal to the length of the first element $(a / h=0.181)$ as shown in Figure 4. For the pure tension and bending loads shown in Figures 7(a) and (b), energy 
release rates were also calculated using the analytical expressions of equation (6). In the example shown in Figure 8 for the tension load case, the parameter $G_{p}$ in equation (6) was computed for $P=$ $5.5 \mathrm{kN}$. The total energy release rate $G_{\mathrm{T}}$ computed using VCCT and the superposed results are identical, since equation (6) is an exact closed form solution. Minor differences for the individual modes, that cannot be explained, are observed. For all permutations of $P$ and $Q$ loads, as shown in Figure 7(c), energy release rates for the combined load case were calculated using equation (9). In this investigation the parameter $G_{P}$ in equation (9) was calculated for a tension load $P=5.5 \mathrm{kN}, G_{Q}$ was determined for a bending load $Q=112.5 \mathrm{kN}$ and $G_{P Q}$ was obtained from one analysis of the combined tension and bending load. Energy release rates obtained from equation (9) were compared to mode I and mode II values calculated using VCCT as shown in Figure 9 for the case where a tension load $P=11.0 \mathrm{kN}$ was applied and $Q$ was varied. For the other permutations of loads the comparisons of only the total energy release rates, $G_{r}$, are shown in Figure 10. The good agreement of results confirms that the superposition technique derived in equation (9) is applicable, in combination with linear finite element analysis and VCCT to determine the unknown parameters, provided the structure shows a linear load/deflection behavior.

\section{A MODIFIED TECHNIQUE FOR NONLINEAR DEFORMATION BEHAVIOR}

For the investigation of the combined axial tension and bending load case as shown in Figures 2(c) and 5, nonlinear finite analyses were used since this allowed the axial load to rotate with the specimen as it deformed under the transverse load and accounted for the membrane stiffening effect caused by the axial load. In this case the superposition technique derived for the linear case in the previous section (equations (8) and (9)) is no longer applicable and a modified method needs to be developed.

An analytical expression was suggested in reference 4 that is primarily a modification of equation (8) derived in the previous section. The external tension load, $P$, and bending load, $Q$, in the analytical expression were replaced with the local force resultant $N_{X X}$ and moment resultant $M_{X X}$, yielding

$$
G=G_{\mathrm{mm}} M_{\mathrm{xx}}^{2}+2 G_{\mathrm{mn}} M_{\mathrm{xx}} N_{\mathrm{xx}}+G_{\mathrm{nn}} N_{\mathrm{xx}}^{2},
$$

where $G_{\mathrm{mm}}$ and $G_{\mathrm{nn}}$ are unknown parameters determined from a pure tension and a pure bending load case and $G_{\mathrm{mn}}$ is an unknown combined tension and bending parameter. The local force and moment resultants are calculated at the flange tip as shown in Figure 11. Location and calculation of the force and moment resultants. For improved accuracy, the terms related to the transverse shear force resultant, $Q_{\mathrm{xy}}$, were also included in expression (10) yielding 


$$
G=G_{\mathrm{mm}} M_{\mathrm{xx}}^{2}+2 G_{\mathrm{mn}} M_{\mathrm{xx}} N_{\mathrm{xx}}+G_{\mathrm{nn}} N_{\mathrm{xx}}^{2}+2 G_{\mathrm{mq}} M_{\mathrm{xx}} Q_{\mathrm{xy}}+2 G_{\mathrm{nq}} N_{\mathrm{xx}} Q_{\mathrm{xy}}+G_{\mathrm{qq}} Q_{\mathrm{xy}}^{2}
$$

Equation (11) may be written in matrix from as

$$
G=\left[\begin{array}{llllll}
M_{\mathrm{xx}}^{2} & 2 M_{\mathrm{xx}} N_{\mathrm{xx}} & N_{\mathrm{xx}}^{2} & 2 M_{\mathrm{xx}} Q_{\mathrm{xy}} & 2 N_{\mathrm{xx}} Q_{\mathrm{xy}} & Q_{\mathrm{xy}}^{2}
\end{array}\right] \cdot\left[\begin{array}{c}
G_{\mathrm{mm}} \\
G_{\mathrm{mn}} \\
G_{\mathrm{nn}} \\
G_{\mathrm{mq}} \\
G_{\mathrm{nq}} \\
G_{\mathrm{qq}}
\end{array}\right] .
$$

Unlike the linear case where a pure tension or a pure bending load case alone may be used to determine one of the unknown parameters, nonlinear analysis of the pure tension and pure bending load case yielded a combination of $M_{\mathrm{xx}}$ and $N_{\mathrm{xx}}$ at the flange tip due to the load eccentricity (tension load) and large displacements (bending load). Therefore, the constants $G_{\mathrm{ij}}(\mathrm{i}, \mathrm{j}=\mathrm{m}, \mathrm{n}, \mathrm{q})$ could not be determined simply from the pure tension and bending load cases. Consequently, all six constants were calculated from a set of six simultaneous linear equations corresponding to six unique loading combinations solved previously, using nonlinear FE analyses. This yields $G_{\mathrm{k}}(k=1, \ldots, 6)$.

$$
\left[\begin{array}{l}
G_{1} \\
G_{2} \\
G_{3} \\
G_{4} \\
G_{5} \\
G_{6}
\end{array}\right]=\left[\begin{array}{llllll}
M_{1}^{2} & 2 M_{1} N_{1} & N_{1}^{2} & 2 M_{1} Q_{1} & 2 N_{1} Q_{1} & Q_{1}^{2} \\
M_{2}^{2} & 2 M_{2} N_{2} & N_{2}^{2} & 2 M_{2} Q_{2} & 2 M_{2} Q_{2} & Q_{2}^{2} \\
M_{3}^{2} & 2 M_{3} N_{3} & N_{3}^{2} & 2 M_{3} Q_{3} & 2 M_{3} Q_{3} & Q_{3}^{2} \\
M_{4}^{2} & 2 M_{4} N_{4} & N_{4}^{2} & 2 M_{4} Q_{4} & 2 M_{4} Q_{4} & Q_{4}^{2} \\
M_{5}^{2} & 2 M_{5} N_{5} & N_{5}^{2} & 2 M_{5} Q_{5} & 2 M_{5} Q_{5} & Q_{5}^{2} \\
M_{6}^{2} & 2 M_{6} N_{6} & N_{6}^{2} & 2 M_{6} Q_{6} & 2 M_{6} Q_{6} & Q_{6}^{2}
\end{array}\right] \cdot\left[\begin{array}{c}
G_{\mathrm{mm}} \\
G_{\mathrm{mn}} \\
G_{\mathrm{nn}} \\
G_{\mathrm{mq}} \\
G_{\mathrm{nq}} \\
G_{\mathrm{qq}}
\end{array}\right] .
$$

Further, the local force and moment resultants $N_{\mathrm{xx}}, M_{\mathrm{xx}}$, and $Q_{\mathrm{xy}}$ for all six unique loading combinations were calculated at the flange tip using the equations shown in Figure 11 by integrating stresses determined in the nonlinear FE analyses yielding $N_{\mathrm{k}}, M_{\mathrm{k}}$, and $Q_{\mathrm{k}}(k=1, \ldots, 6)$. The system of six equations was then solved for the unknown $G_{i j}$ values. With the constants $G_{i j}$ known, $G$ could then be calculated from the force and moment resultants $N_{\mathrm{xx}}, Q_{\mathrm{xy}}$ and $M_{\mathrm{xx}}$ for any combined tension/bending load case using the technique described by equation (11). The term $G$ is used here for the total energy release rate or for a mixed mode energy release rate component. Hence, the calculation of each of the individual modes $G_{p}, G_{I I}$ or $G_{T}$ requires a unique set of $G_{\mathrm{ij}}$ constants each. This means that equation (13) needs to be solved individually for each fracture mode (I,II) before equation (11) is used to obtain the individual modes $G_{p}, G_{I I}$ or $G_{T}$

The analytical expressions (10) and (11) were derived with the objective of developing a simple procedure to calculate the strain energy release rate if the specimen shows a nonlinear load/deflection behavior. The expressions may also be used if the specimen exhibits a linear 
load/deflection behavior. Calculating the force and moment resultants and solving equation (13) to obtain a unique set of constants $G_{\mathrm{ij}}$ for each fracture mode, however, appears to be cumbersome in this case because $\mathrm{FE}$ analysis needs to be performed for six unique combined load cases to determine the unknown parameters $G_{i j}$. In contrast, the use of expression (8) is simpler, because the external loads are known and only three load cases need to be analyzed to determine $G_{P}, G_{Q}$ and $G_{P Q}$.

The matrix equation (13), which contains the terms of local force and moment resultants $N_{\mathrm{k}}, M_{\mathrm{k}}$, and $Q_{\mathrm{k}}$, may become singular. For linear load/deflection behavior this will occur if at least one of the six load cases selected to calculate $N_{\mathrm{r}}, M_{\mathrm{k}}, Q_{\mathrm{k}}$ and $G_{\mathrm{r}}$ is not independent from the other cases, but simply a linear combination of any of them. For nonlinear load/deflection behavior it is not easily predictable under which circumstances the matrix might become singular. In both cases, however, six unique load cases need to be selected to avoid matrix singularity and solve equation (13) for the unknown parameters.

The energy release rates were calculated using the modified method (equation (11)) for all permutations of axial loads, $P$, and transverse displacements, $v_{\max }$, shown in Figure 5 . The unknown parameters $G_{\mathrm{ij}}$ in equation (13) were obtained from nonlinear finite element analyses of six different unique load cases $\left(P_{1}=0.0, v_{1}=30.9 \mathrm{~mm} ; P_{2}=4.5 \mathrm{kN}, v_{2}=7.5 \mathrm{~mm} ; P_{3}=4.5 \mathrm{kN}, v_{3}=\right.$ $\left.30.9 \mathrm{~mm} ; P_{4}=9.0 \mathrm{kN}, v_{4}=7.5 \mathrm{~mm} ; P_{5}=9.0 \mathrm{kN}, v_{5}=30.9 \mathrm{~mm} ; P_{6}=17.8 \mathrm{kN}, v_{6}=30.9 \mathrm{~mm}\right)$. Calculated mixed-mode results were compared with the energy release rates obtained directly from nonlinear finite element analyses using VCCT as shown in Figure 12 for a case where only one axial load of $P=4.5 \mathrm{kN}$ and multiple transverse displacements, $v_{\max }$, were applied. As expected, the results were identical for the two cases which had been selected to determine the unknown parameters $G_{i j}$. For the other load combinations, $G_{p}, G_{l l}$ and $G_{T}$ were in excellent agreement. Total energy release rates calculated for all axial load and transverse displacement permutations are shown in Figure 13. For the remaining load combinations, calculated strain energy release rates differed by less than $5 \%$ when compared to results computed directly from nonlinear finite element analysis using VCCT. Good results, however, were only obtained if the six unique load combinations to determine the unknown parameters $G_{\mathrm{ij}}$ include the upper and lower limits of load combinations as shown in Figure 13. The modified method should be used to interpolate results for different load combinations. Extrapolation may lead to inaccurate results.

Hence, it was possible to derive a technique which was applicable for nonlinear deformation of the specimen. The expression derived for the linear case was modified such that terms of the external forces were replaced by internal force and moment resultants. The energy release rates calculated using this technique seemed sufficiently accurate for preliminary design studies. However, while external forces are known, force and moment resultants at the flange tip need to be calculated analytically or computed from finite element analysis. For the current study of 
the combined axial tension and bending load case, nonlinear finite analyses were used to calculate the force and moment resultants. This requires about the same computational effort as directly computing the energy release rates from nonlinear analyses using the virtual crack closure technique. An additional effort is required to obtain the unknown parameters $G_{\mathrm{ij}}$. The use of the technique as given in equation (11) may therefore become time consuming and less appealing for quickly calculating energy release rates for a large number of new load combinations from a set of known results. Furthermore, this process may have to be repeated for each new delamination length modeled to obtain the distribution of $G_{P} G_{I I}$ and $G_{T}$ as a function of delamination length. Consequently, another approach was developed for the simulation of delamination growth.

\section{SIMULATION OF DELAMINATION GROWTH}

The techniques developed in the previous sections focused on simple procedures to calculate the strain energy release rate for various combinations of loads from results previously computed for other load cases. A related problem is the simulation of delamination growth where mixed mode energy release rates need to be calculated as a function of delamination length, $a$. The shape of the $G$ versus $a$ curves for $G_{p} G_{I I}$ and $G_{T}$ yield information about stability of delamination growth and often dictate how these energy release rates are used to predict the onset of delamination [16]. During the nonlinear finite element analyses, the delaminations are extended and strain energy release rates are computed at virtual delamination lengths using the virtual crack closure technique. For preliminary design studies with several load cases of interest, delamination positions and lengths need to be checked continuously. Hence, the amount of computation time necessary may become excessive. Therefore fast and accurate alternatives need to be developed.

\section{REVIEW OF SIMULATED DELAMINATION PROPAGATION USING A SERIES OF NONLINEAR FINITE ELEMENT ANALYSES}

The schematics of the deformed geometries, the boundary conditions, and the loads examined in this part of the study are shown in Figure 2 for all three load cases. The boundary conditions considered in the simulations were chosen to model the actual test from references 6 and 7 as closely as possible. For the tension and bending case, the mean loads reported for the point of damage initiation were applied. At this point, matrix cracks are likely to form. To be consistent with the combined axial tension and bending tests, a constant axial load, $P=17.8 \mathrm{kN}$, was applied in a first load step while transverse loads remained zero. In a second load step, the axial load was kept constant while the load orientation rotated with the specimen as it deformed under the 
transverse load. In the FE simulation, a prescribed displacement was applied which corresponded to the average of the transverse stroke $(V=31 \mathrm{~mm})$ for which flange debond occurred $[6,7]$.

The initial matrix crack was modeled on one flange tip perpendicular to the flange taper as suggested by the microscopic investigation and shown in Figure 3 . The model of the discrete matrix crack and delamination is shown in Figure 4. During the nonlinear finite element analyses, the delaminations were extended and strain energy release rate components were computed as a function of delamination length using the virtual crack closure technique. The delamination lengths, $a$, were measured from the end of the initial matrix crack as shown in Figure 4. The delamination was extended in twelve increments up to about $0.6 \mathrm{~mm}(a / h=3.2)$ which corresponds to a length where matrix crack branches were observed in the experiments as shown in Figure 3(b). The simulated delamination propagation therefore required 12 nonlinear $\mathrm{FE}$ analyses for each load case, consequently 36 analyses for all three load cases. The results plotted in Figures 14 through 16 show that $G_{\mathrm{I}}$ increases monotonically for all load cases while $G_{\mathrm{I}}$ begins to level off at the longest delamination lengths $[6,7]$. These results were intended as reference solutions to be compared with results from the superposition method in the following section.

\section{A LOCAL TECHNIQUE FOR SIMULATED DELAMINATION GROWTH}

In the previous sections, simple quadratic expressions were developed which made it possible to calculate the strain energy release rate for various load combinations. In this part of the investigation a technique was developed where the forces and displacements at the crack tip (see Figure 6) obtained from three linear analyses are superposed. The calculated energy release rates for one delamination length are matched with the corresponding results from one nonlinear finite element analysis and a correction factor is determined. This correction factor is then used to size the results obtained from linear analyses for all other delamination lengths.

Only one nonlinear finite element analysis was performed for each load case using a full model of the damaged specimen as shown in Figure 4. Loads measured at the onset of damage as shown in Figure 2 and discussed in the previous paragraph were simulated. Mode I and mode II

energy release rates $G_{\mathrm{I}, \mathrm{NL}}$ and $G_{\mathrm{IIN \textrm {NL }}}$ were computed for a delamination length equal to the length of the first element $(a / h=0.181)$ as shown in Figure 4. Local force and moment resultants $N_{x x}, Q_{x y}$, and $M_{x x}$ were calculated at the location where the end of the frame or stringer flange meets the skin as shown in Figure 11. Resultants plotted in Figure 17 show that the force resultant $N_{\mathrm{xx}}$ is zero for the three-point bending test as it is free of axial tension. Also as expected, there is a small transverse shear, which is non zero. For the tension test, in addition to the membrane resultant, a bending moment is present due to the load eccentricity in the flange region and the asymmetric 
layup of the combined skin and flange laminate with respect to the neutral axis. The shear force resultant $Q_{\mathrm{xy}}$ is nearly zero, as expected. For the ATB test, calculated membrane and moment resultants lie between the computed pure tension and pure bending values [7]. Due to the high transverse load during the tests, the shear force resultant is significant for this load condition. It was assumed that these local force and moment resultants calculated at the flange tip vary only slightly when the delamination is extended.

Three local sub-models (shown in Figure 18) were then developed to simulate delamination growth using a linear analysis. The local sub-model consisted of a small section of the original model around the location where the end of the frame or stringer flange meets the skin. To avoid any disturbance associated with the load introduction, the length of the model to the left of the damage $\left(d_{1}\right)$ was about three times the skin thickness and the length of the model to the right of the damage location $\left(d_{2}\right)$ was about three times the skin plus flange thickness $\left(t_{\mathrm{s}}+t_{\mathrm{f}}\right)$. The mesh used for the local sub-model is the same as the mesh of the full model shown in Figure 4. As shown in Figure 18(a), boundary conditions for all local sub-models were selected to prevent the translations in the plane and rotation of the model. Three unit load cases were simulated as shown in Figures 18(b) through (d) and the delamination was extended as explained in the paragraph above. External loads were chosen such that a unit force resultant $N_{x x} Q_{x y}$ or unit moment resultant $M_{x x}$ exists at the reference station at the flange tip. For the unit transverse shear load case, a counter reacting moment, $M_{C}$, needs to be applied at the end of the model to assure a pure shear force resultant $Q_{x y}$ at the flange tip. To facilitate the simulation of the external moment (Figure 18(c) and (d)) three-noded quadratic beam elements with rotational degrees of freedom were used for the simulation of the load introduction zone, $s$, which had the same length as the adjacent plane strain elements (Figure 18(a)). A rectangular beam cross section was selected to model the square cross section of the skin. The beams were connected to the two-dimensional plane strain model of the local section using multi-point constraints to enforce appropriate translations and rotations. This procedure was explained for the combined axial tension/bending load case and shown earlier in Figure 5. For the beam model, smeared orthotropic material properties were calculated for the skin laminate and used as material input data.

For each unit load case (index $N, M, Q$ ), the delaminations were extended and a linear finite element analysis was performed for each length $a$. For each simulation, forces $X_{\mathrm{Ni}_{\mathrm{i}}}^{\prime}(a), X_{\mathrm{Mi}}^{\prime}(a)$, $X_{\mathrm{Qi}^{2}}(a)$, and $Y_{\mathrm{Ni}}(a), Y_{\mathrm{Mi}}(\mathrm{a}), Y_{\mathrm{Qj}}(a)$, at the delamination tip at node $\mathrm{i}$ and the relative displacements $\Delta u_{\mathrm{Nm}}^{\prime}(a), \Delta u_{\mathrm{Mm}}^{\prime}(a), \Delta u_{\mathrm{Qm}}^{\prime}(a)$, and $\Delta v_{\mathrm{Nm}}^{\prime}(a), \Delta v_{\mathrm{Mm}}^{\prime}(a), \Delta v_{\mathrm{Qm}}^{\prime}(a)$, at the corresponding node $\mathrm{m}$ behind the delamination tip were retrieved from the finite element results (see Figure 6). Forces at node $\mathrm{j}$ and relative displacements at node $\ell$ were also obtained. In a second step, forces and relative displacements for each of unit load cases were scaled by multiplying with the corresponding force and moment resultant $N_{x x^{\prime}} Q_{x y}$ and $M_{x x}$ obtained from the nonlinear analysis of the full model. The 
scaled forces and displacements were then superposed yielding

$$
\begin{aligned}
& Y_{\mathrm{i}}(a)=N_{\mathrm{xx}} \cdot Y_{\mathrm{Ni}}(a)+M_{\mathrm{xx}} \cdot Y_{\mathrm{Mi}}(a)+Q_{\mathrm{xz}} \cdot Y_{\mathrm{Qj}}(a) \\
& Y_{\mathrm{j}}(a)=N_{\mathrm{xx}} \cdot Y_{\mathrm{Nj}}(a)+M_{\mathrm{xx}} \cdot Y_{\mathrm{Mj}}(a)+Q_{\mathrm{xz}} \cdot Y_{\mathrm{Qj}}(a) \\
& \Delta v_{\mathrm{m}}^{\prime}(a)=N_{\mathrm{xx}} \cdot \Delta v_{\mathrm{Nm}}^{\prime}(a)+M_{\mathrm{xx}} \cdot \Delta v_{\mathrm{Mm}}^{\prime}(a)+Q_{\mathrm{xz}} \cdot \Delta v_{\mathrm{Qm}}(a) \\
& \Delta v_{\ell}^{\prime}(a)=N_{\mathrm{xx}} \cdot \Delta v_{\mathrm{N} \ell}^{\prime}(a)+M_{\mathrm{xx}} \cdot \Delta v_{\mathrm{M} \ell}^{\prime}(a)+Q_{\mathrm{xz}} \cdot \Delta v_{\mathrm{Q} \ell}^{\prime}(a)
\end{aligned}
$$

Forces $X_{\mathrm{i}}^{\prime}(a)$ and $X_{\mathrm{j}}^{\prime}(a)$ as well as relative displacements $\Delta u_{\mathrm{m}}^{\prime}(a)$ and $\Delta u{ }_{\ell}^{\prime}(a)$, were obtained accordingly. All forces $\left(X_{\mathrm{i}}^{\prime}(a), X_{\mathrm{j}}^{\prime}(a)\right.$, and $\left.Y_{\mathrm{j}}^{\prime}(a), Y_{\mathrm{j}}^{\prime}(a)\right)$, and relative displacements $\left(\Delta u_{\mathrm{m}}^{\prime}(a)\right.$, $\Delta u_{\ell}^{\prime}(a)$, and $\left.\Delta v_{\mathrm{m}}^{\prime}(a), \Delta v_{\ell}^{\prime}(a)\right)$ obtained, served as input for the virtual crack closure technique

$$
\begin{aligned}
& G_{\mathrm{l}}(a)=-\frac{c_{\mathrm{I}}}{2 \Delta a} \cdot[Y_{\mathrm{i}}^{\prime}(a) \cdot \underbrace{\left(v_{\mathrm{m}}^{\prime}(a)-v_{\mathrm{m}}^{\prime}(a)\right)}_{\Delta v_{\mathrm{m}}^{\prime}(a)}+Y_{\mathrm{i}}^{\prime}(a) \cdot \underbrace{\left(v_{\ell}^{\prime}(a)-v_{i}^{\prime}(a)\right)}_{\Delta v_{\ell}^{\prime}(a)}] \\
& G_{\mathrm{II}}(a)=-\frac{c_{\mathrm{II}}}{2 \Delta a}[X_{\mathrm{i}}^{\prime}(a) \cdot \underbrace{\left(u_{\mathrm{m}}^{\prime}(a)-u_{\mathrm{m}}^{\prime}(a)\right)}_{\Delta u_{\mathrm{m}}^{\prime}(a)}+X_{\mathrm{i}}^{\prime}(a) \cdot \underbrace{\left(u_{\ell}^{\prime}(a)-u_{\ell}^{\prime}(a)\right)}_{\Delta u_{\ell}^{\prime}(a)}] .
\end{aligned}
$$

The correction factors $c_{\mathrm{I}}$ and ${ }^{\circ} c_{\mathrm{II}}$ for mode I and mode II, respectively, were introduced in order to size the results for $G_{\mathrm{I}}$ and $G_{\mathrm{II}}$ obtained from the superposition procedure (equations (15) and (16)) along the delamination length. One set of correction factors $c_{\mathrm{I}}$ and $c_{\mathrm{II}}$ was determined for the entire study by matching the $G_{\mathrm{I}}$ and $G_{\mathrm{II}}$ results obtained for the initial crack $(a / h=0.181)$ with $G_{\mathrm{I}, \mathrm{NL}}$ and $G_{\mathrm{IINL}}$ computed from the initial nonlinear analysis. This is accomplished by calculating $G_{\mathrm{I}}$ $(a / h=0.181)$ and $G_{\mathrm{II}}(a / h=0.181)$ first with the correction factors set to $c_{\mathrm{I}}=c_{\mathrm{II}}=1$ and then solving for the correction factors

$$
c_{\mathrm{I}}=\frac{G_{\mathrm{I}, \mathrm{NL}}(a / h=0.181)}{G_{\mathrm{I}}(a / h=0.181)} \quad \text { and } \quad c_{\mathrm{II}}=\frac{G_{\mathrm{II}, \mathrm{NL}}(a / h=0.181)}{G_{\mathrm{II}}(a / h=0.181)} .
$$

The correction factors obtained for the tension, three-point bending and combined axial tension/bending load case are given in Table 2. For the pure tension and the axial tension/bending load cases the correction factors are relatively large when compared to the factors calculated for the pure bending load case. This is most likely related to the distinct nonlinear load/deflection behavior of the specimens subjected to these loadings. Hence, large correction factors are required to match the results obtained from the three linear unit load cases with those obtained directly from nonlinear FE analysis using VCCT. Consequently, for a nearly linear load/deflection behavior - as observed 
during the bending test - a much smaller correction factor is required. The load/deformation behavior of the specimens for all three load cases is discussed in detail in references 6 and 7 .

For the tension, three-point bending and combined axial tension and bending load case, mixed mode energy release rates were calculated using the superposition technique described above and given in equations (14) through (17). The results were included in the plots of Figures 14 through 16. For the initial matrix crack length ( $a / h=0.181)$ the results are identical, as this point was chosen to match the results and calculate the corrections factors (see equation (17)). The correction factors obtained were kept constant during the simulation of delamination growth. The obtained mixed mode energy release rates show that $G_{\text {II }}$ increases monotonically for all load cases while $G_{\mathrm{I}}$ begins to level off at the longest delamination lengths. For the bending load case the results were in excellent agreement with energy release rates calculated directly from nonlinear finite element results using VCCT along the entire delamination length. This may be attributed to the fact that the load/deflection behavior of the specimen under this load is nearly linear and therefore can closely be approximated by the linear analyses of the local sub-models. Along the entire delamination length investigated, results were in good agreement for the other load cases as well. As the delamination length becomes longer however, the results obtained from the superposition technique begin to deviate slightly from the values calculated directly from nonlinear finite element analyses. For long delamination lengths it might therefore be advantageous to calculate several reference solutions for different delamination lengths from the full model using nonlinear analysis and update the corrections factors.

As mentioned in the previous paragraph, a total of twelve nonlinear analyses were necessary when using the conventional approach to obtain the results for one load case as shown in Figures 14 through 16 . The superposition technique described above required only one nonlinear analysis of the full model for each load case and 36 linear analyses of the local sub-model. Even for one load case this means a considerable reduction in CPU time. Although additional modeling effort is required to create the local sub-model, the results indicate that the proposed technique is very efficient for large parametric studies which may occur during preliminary design where multiple load combinations must be considered.

\section{CONCLUDING REMARKS}

Three simple procedures were developed to determine strain energy release rates, $G$, in composite skin/stringer specimens for various combinations of in-plane and out-of-plane loading conditions. These procedures may be used for parametric design studies in such a way that only a few finite element computations will be necessary for a study of many load combinations. Since 
energy is a quadratic function of the applied loads, it was not possible to simply superpose and add the energy release rates from separate load cases. A simple quadratic expression was previously developed to calculate the strain energy release rate for any combination of loads. To validate the procedures, results obtained from the quadratic expressions were compared to mode I and mode II strain energy release rate contributions, which were calculated from nonlinear twodimensional plane-strain finite element analyses using the virtual crack closure technique.

For the first technique, the boundary conditions for the tension, bending and combined tension/bending load case were chosen in such a manner that the specimen deformation was assumed to be a linear function of the applied loads. Therefore a linear finite element solution was used to compute the strain energy release rate for various multi-axial load combinations. The technique involved solving three unknown parameters needed to determine the energy release rates from a simple tension, a simple bending, and one combined tension/bending load case. Excellent results were obtained when the external loads were used. This superposition technique, however, was only applicable if the structure exhibits a linear load/deflection behavior.

Consequently, a second modified technique was derived which was applicable also in the case of nonlinear load/deformation behavior. The expression derived for the linear case was modified such that terms of the external forces were replaced by internal force and moment resultants at the flange tip. The energy release rates calculated using this technique seemed sufficiently accurate for preliminary design studies. However, force and moment resultants at the flange tip need to be calculated and additional effort is required to obtain six unknown parameters from a set of six simultaneous linear equations to determine the energy release rates. This procedure, therefore, was not time efficient, and hence, less appealing.

Finally, a third procedure was developed to calculate mixed mode energy release as a function of delamination lengths. This procedure required only one nonlinear finite element analysis of the specimen with a single delamination length to obtain the force and moment resultants at the flange tip and a reference solution for the energy release rates. It was assumed that the local force and moment resultants calculated at the flange tip vary only slightly when the delamination is extended. Therefore it is sufficient to calculate these resultants for one delamination length. The delamination was subsequently extended in three separate linear models of the local area in the vicinity of the delamination subjected to unit loads. Forces and displacements computed at the delamination tip for the unit load cases were superposed and used in the virtual crack closure technique to obtain the distribution of $G$ with delamination length. Results were in good agreement with energy release rates calculated directly from nonlinear finite element results using VCCT. Although additional modeling effort is required to create the local sub-model, this superposition technique is very efficient for large parametric studies which may occur during preliminary design where multiple load combinations must be considered. 


\section{ACKNOWLEDGMENTS}

This work was performed as part of a Cooperative Research and Development Agreement (CRDA) between the U.S. Army Research Laboratory, Vehicle Technology Directorate located at NASA Langley Research Center, and Boeing, Philadelphia.

\section{REFERENCES}

[1] Minguet, P. J., Fedro, M.J., O'Brien, T. K., Martin, R. H., Ilcewicz, L. B., Awerbuch, J., and Wang, A., "Development of a Structural Test Simulating Pressure Pillowing Effects in a Bonded Skin/Stringer/Frame Configuration," Proceedings, Fourth NASADoD Advanced Composites Technology Conference, Salt Lake City, UT, June 1993.

[2] Minguet, P. J. and O'Brien, T. K., "Analysis of Test Methods for Characterizing Skin/Stringer Debonding Failures in Reinforced Composite Panels," Composite Materials: Testing and Design, Twelfth Volume, ASTM STP 1274, August 1996, pp. 105-124.

[3] Minguet, P. J. and O'Brien, T. K., "Analysis of Composite Skin/Stringer Bond Failures Using a Strain Energy Release Rate Approach," Proceedings of the Tenth International Conference on Composite Materials, Vol. I, Woodhead Publishing Ltd., 1995, pp. 245-252.

[4] Minguet, P. J., "Analysis of the Strength of the Interface between Frame and Skin in a Bonded Composite Fuselage Panel," Proceedings of the 38th AIAA/ASME/ASCE/AHS/ASC SDM Conference and Exhibit, Kissimmee, Florida, 1997, AIAA-97-1342, pp. 2783-2790.

[5] Cvitkovich, M. K., O'Brien, T. K., and Minguet, P. J., "Fatigue Debonding Characterization in Composite Skin/Stringer Configurations, " Composite Materials: Fatigue and Fracture, Seventh Volume, ASTM STP 1330, 1998, pp. 97-121.

[6] Cvitkovich, M.K., Krueger, R., O'Brien, T.K., and Minguet, P.J. "Debonding in Composite Skin/Stringer Configurations under Multi-Axial Loading," Proceedings of the American Society for Composites, 13th Technical Conference on Composite Materials, ISBN 0-9667220-0-0 CD-ROM, 1998, pp. 1014-1048.

[7] Krueger, R., Cvitkovich, M.K., O'Brien, T.K., and Minguet, P.J. "Testing and Analysis of Composite Skin/Stringer Debonding under Multi-Axial Loading," NASA TM-209097, $A R L-M R-439$, February 1999.

[8] Rybicki, E. F. and Kanninen, M. F., "A Finite Element Calculation of Stress Intensity Factors by a Modified Crack Closure Integral," Eng. Fracture Mech., 9, 1977, pp. 931-938. 
[9] Raju, I. S., "Calculation Of Strain-Energy Release Rates With Higher Order And Singular Finite Elements," Eng. Fracture Mech., 28, 1987, pp. 251-274.

[10] ABAQUS/Standard, "User's Manual, Volume II", Version 5.6, 1996

[11] O'Brien, T. K., Murri, G. B., Hagemeier, R., and Rogers, C., "Combined Tension and Bending Testing of Tapered Composite Laminates," Applied Composite Materials, 1, 1995, pp. 401-413.

[12] Murri, G. B., O'Brien, T. K., and Rousseau, C. Q., "Fatigue Life Methodology for Tapered Composite Flexbeam Laminates," Joumal of the American Helicopter Society, Vol. 43, (2), April 1998, pp. 146-155.

[13] Sun, C. T. and Manoharan, M. G., "Strain Energy Release Rates of an Interfacial Crack Between Two Orthotropic Solids," Journal of Composite Materials, Vol. 23, May 1989, pp. 460-478.

[14] Rajju, I. S., Crews, J.H. and Aminpour, M.A., "Convergence of Strain Energy Release," Eng. Fracture Mech., 30, 1988, pp. 383-396.

[15] Broek, D., Elementary Engineering Fracture Mechanics, 4th revised edition, Kluwer Academic Publishers, ISBN 90-247-2656-5, 1991.

[16] Martin, R. H., "Incorporating Interlaminar Fracture Mechanics Into Design," International Conference on Designing Cost-Effective Composites, IMechE Conference Transactions, London, 15-16 September, 1998, pp. 83-92. 


\section{TABLES}

TABLE 1. MATERIAL PROPERTIES.

\begin{tabular}{ccc}
\hline \multicolumn{3}{c}{ MM6/3501-6 Unidirectional Graphite/Epoxy Tape [3] } \\
\hline$E_{11}=144.7 \mathrm{GPa}$ & $E_{22}=9.65 \mathrm{GPa}$ & $E_{33}=9.65 \mathrm{GPa}$ \\
$v_{12}=0.30$ & $v_{13}=0.30$ & $v_{23}=0.45$ \\
$G_{12}=5.2 \mathrm{GPa}$ & $G_{13}=5.2 \mathrm{GPa}$ & $G_{23}=3.4 \mathrm{GPa}$ \\
& & \\
& CYTEC 1515 Adhesive & \\
\hline$E=1.72 \mathrm{GPa}$ & $v=0.30$ & (assumed isotropic)
\end{tabular}

TABLE 2. CORRECTION FACTORS FOR SCALED ENERGY RELEASE RATES.

\begin{tabular}{ccc}
\hline Tension Load Case & Bending Load Case & $\begin{array}{c}\text { Axial Tension/Bending } \\
\text { Load Case }\end{array}$ \\
\hline$c_{\mathrm{I}}=1.2657$ & $c_{\mathrm{I}}=1.0036$ & $c_{\mathrm{I}}=1.2791$ \\
$c_{\mathrm{II}}=1.2484$ & $c_{\mathrm{II}}=1.0646$ & $c_{\mathrm{II}}=1.1720$ \\
\hline
\end{tabular}



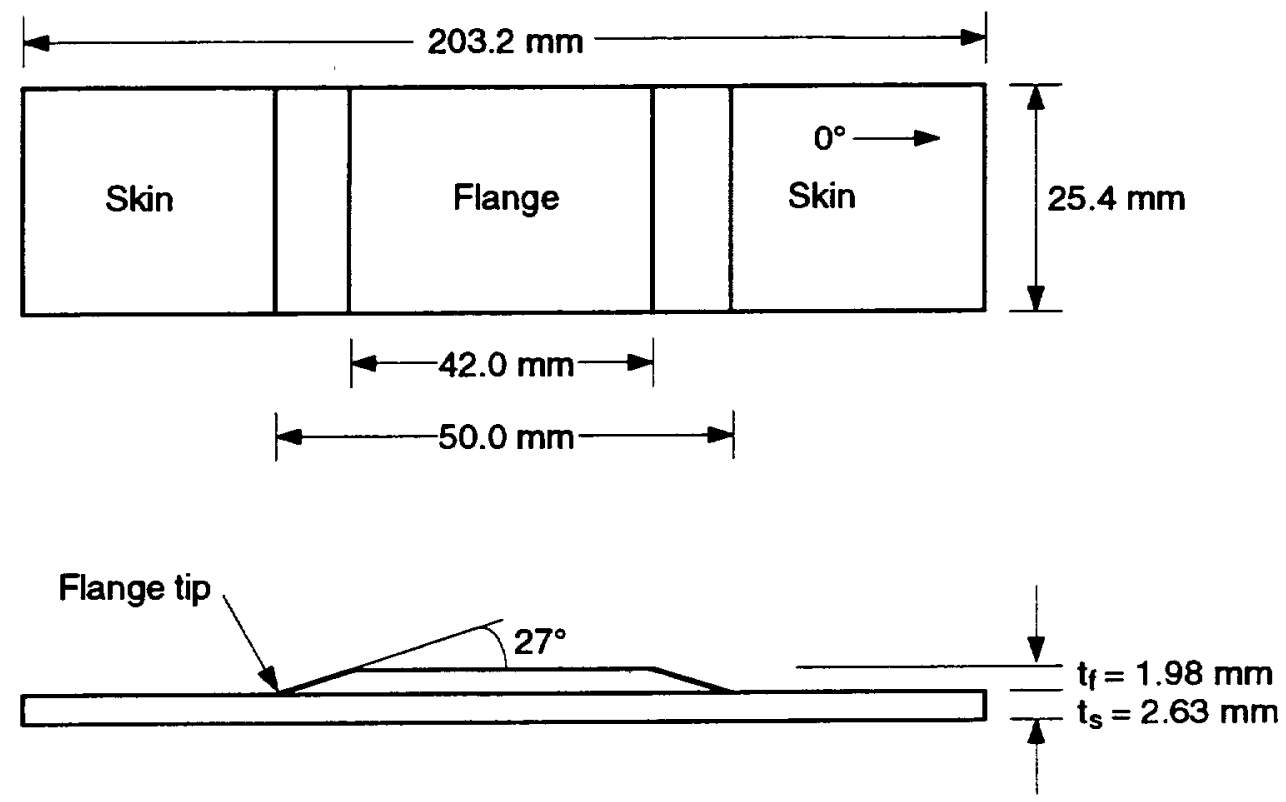

Figure 1. Specimen Configuration. 
- - - undeformed center line

deformed configuration

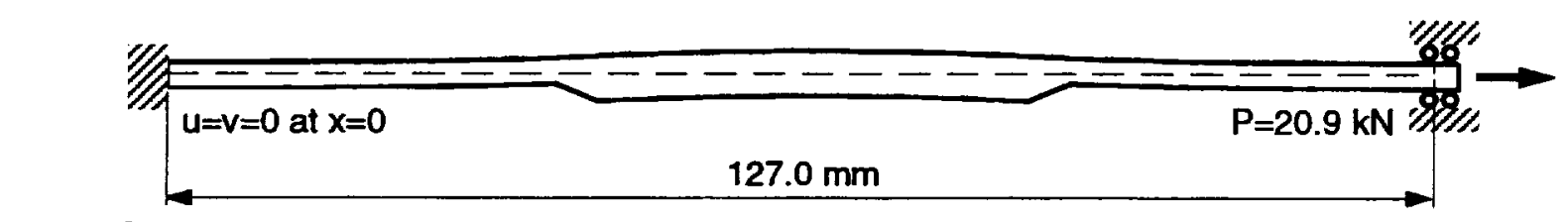

$\Lambda^{y, v, Q}$

$x, u, P$

(a) Tension Specimen
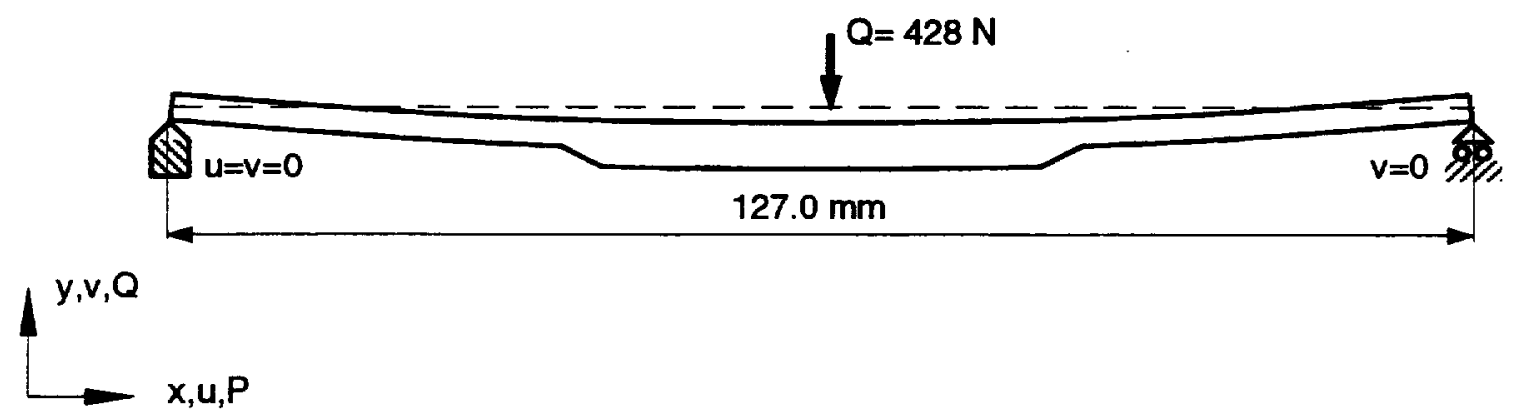

(b) Bending Specimen
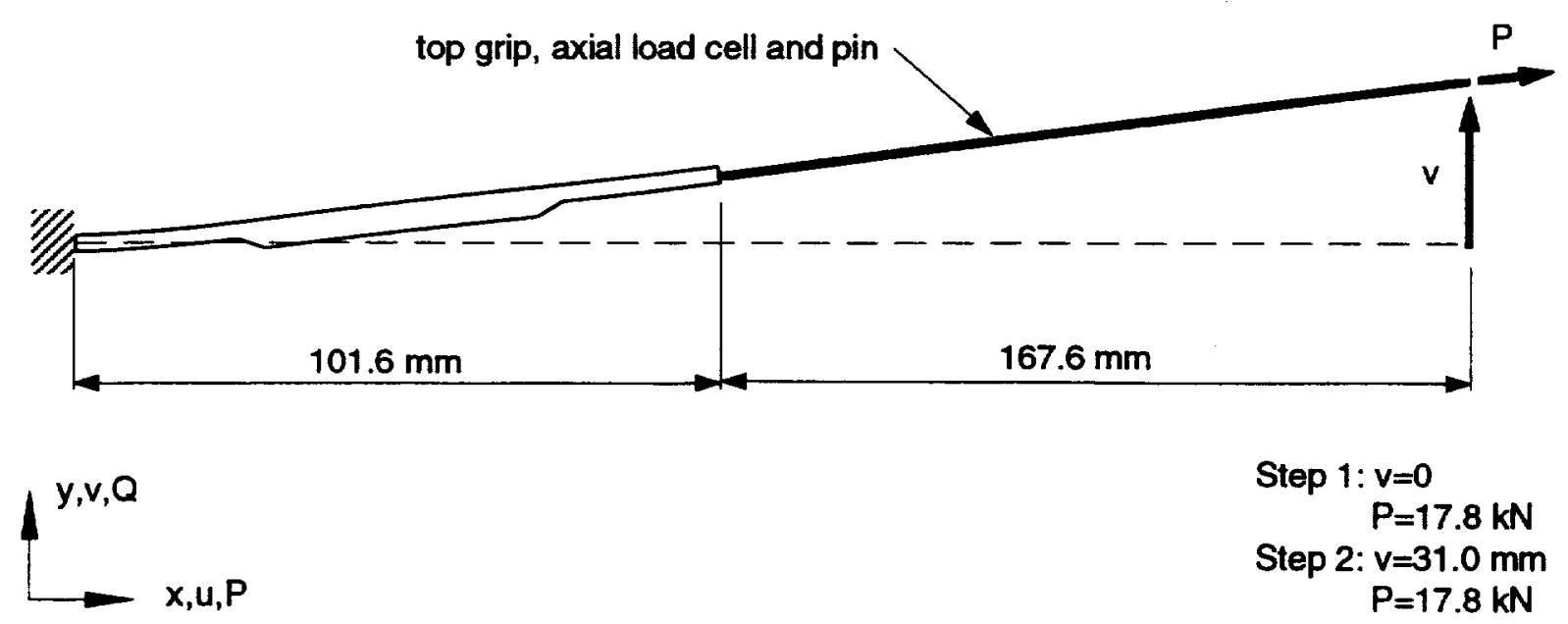

Step 1: $v=0$

$P=17.8 \mathrm{kN}$

Step 2: $v=31.0 \mathrm{~mm}$ $P=17.8 \mathrm{kN}$

(c) Combined Axial Tension/Bending Specimen

Scale Different from (a) and (b)

Figure 2. Deformed Test Specimen Geometries, Load and Boundary Conditions at Damage Initiation $[6,7]$. 


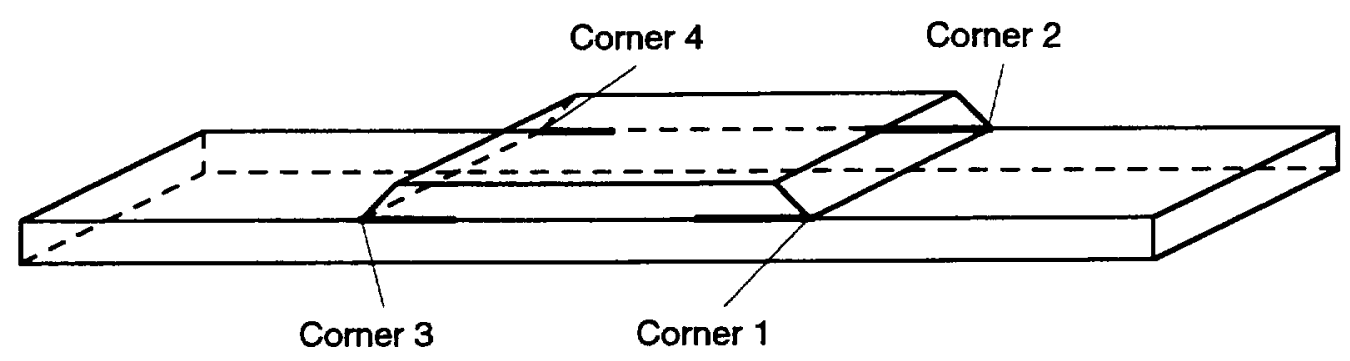

(a) Specimen with Crack Locations.

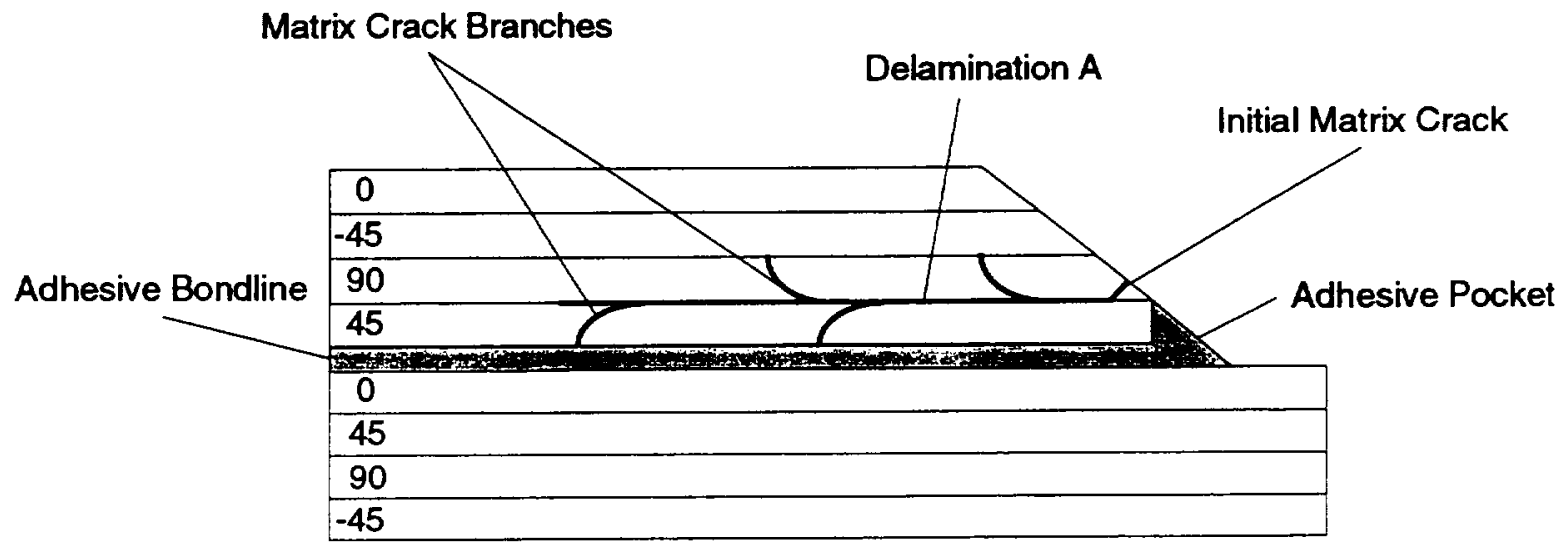

(b) Corners 1 and 4

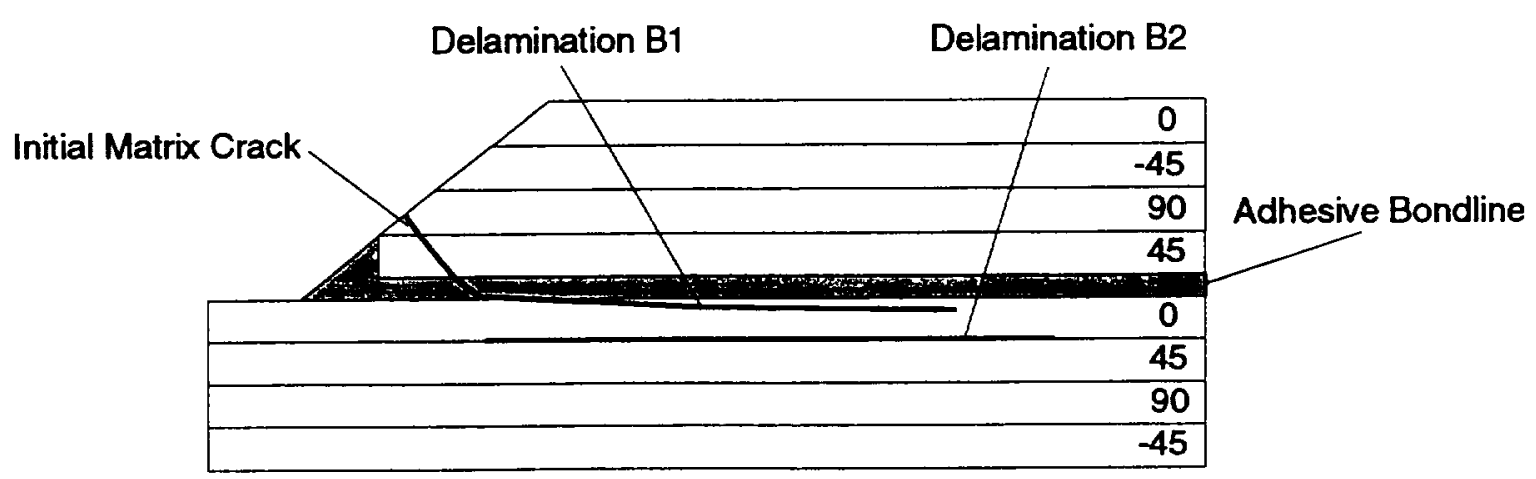

(c) Corners 2 and 3

Figure 3. Typical Damage Patterns [6,7] 

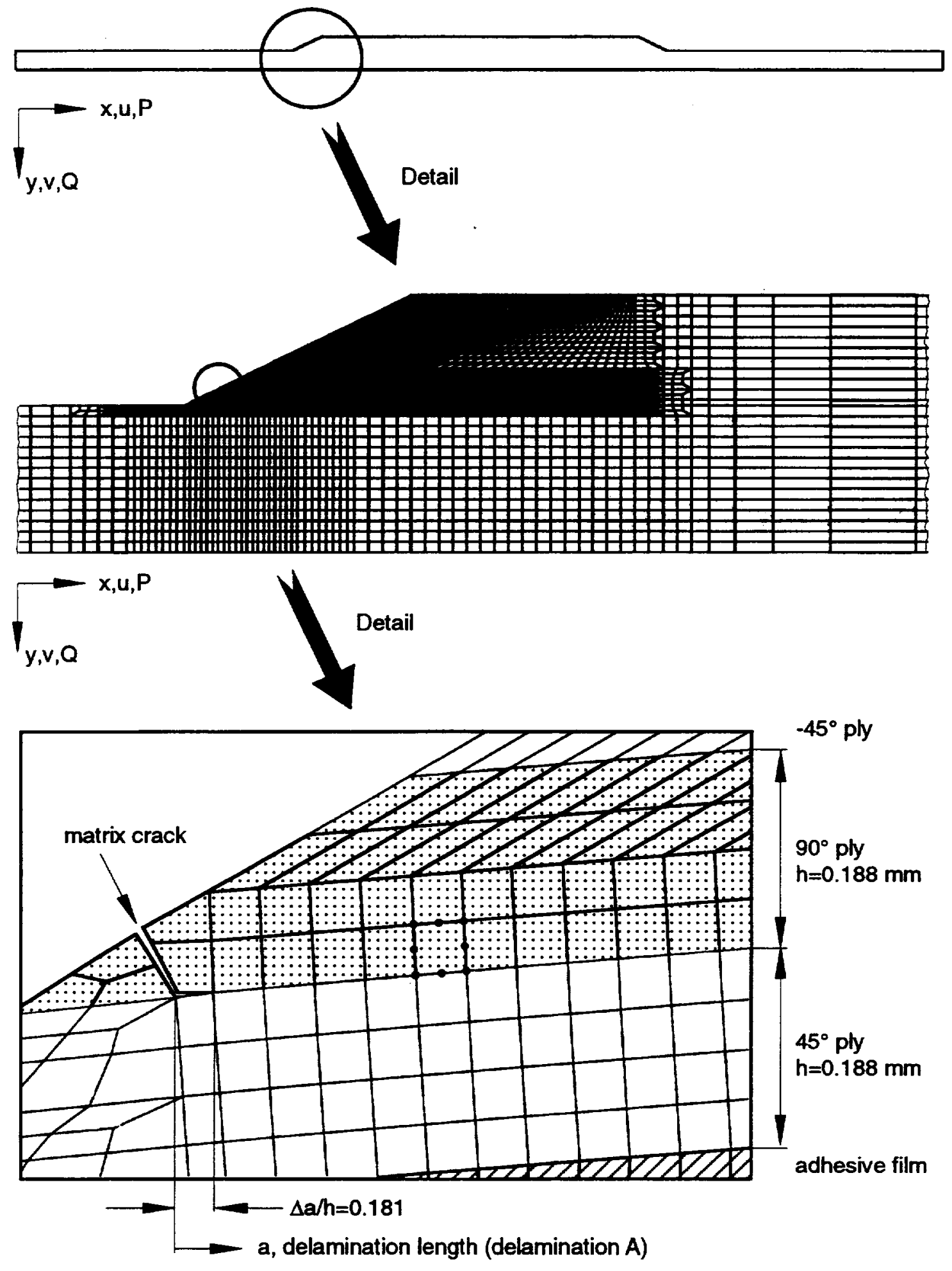

Figure 4. Finite Element Model of a Damaged Specimen. 

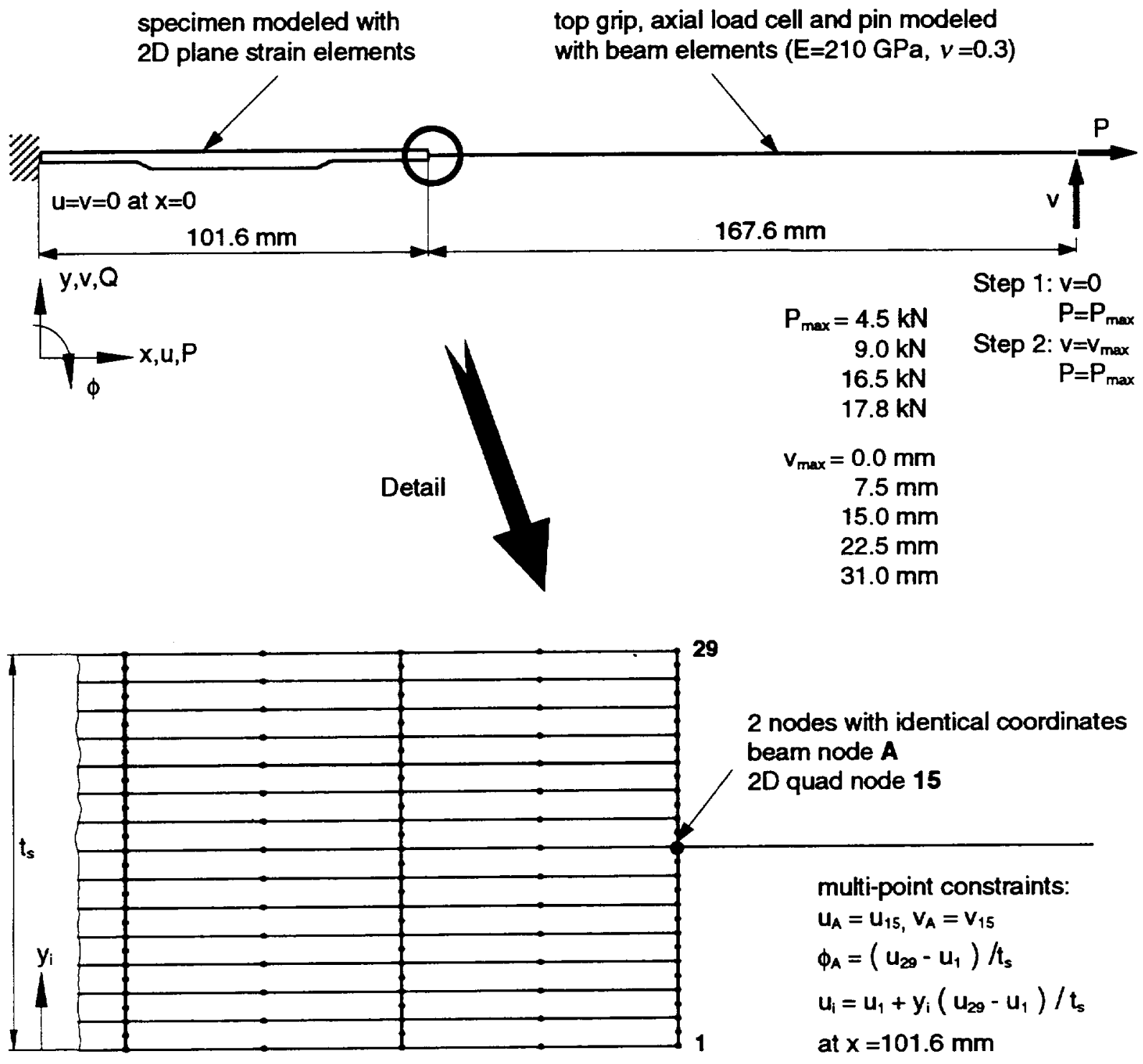

Figure 5. Loads and Boundary Conditions for the Combined Axial Tension and Bending Test. 


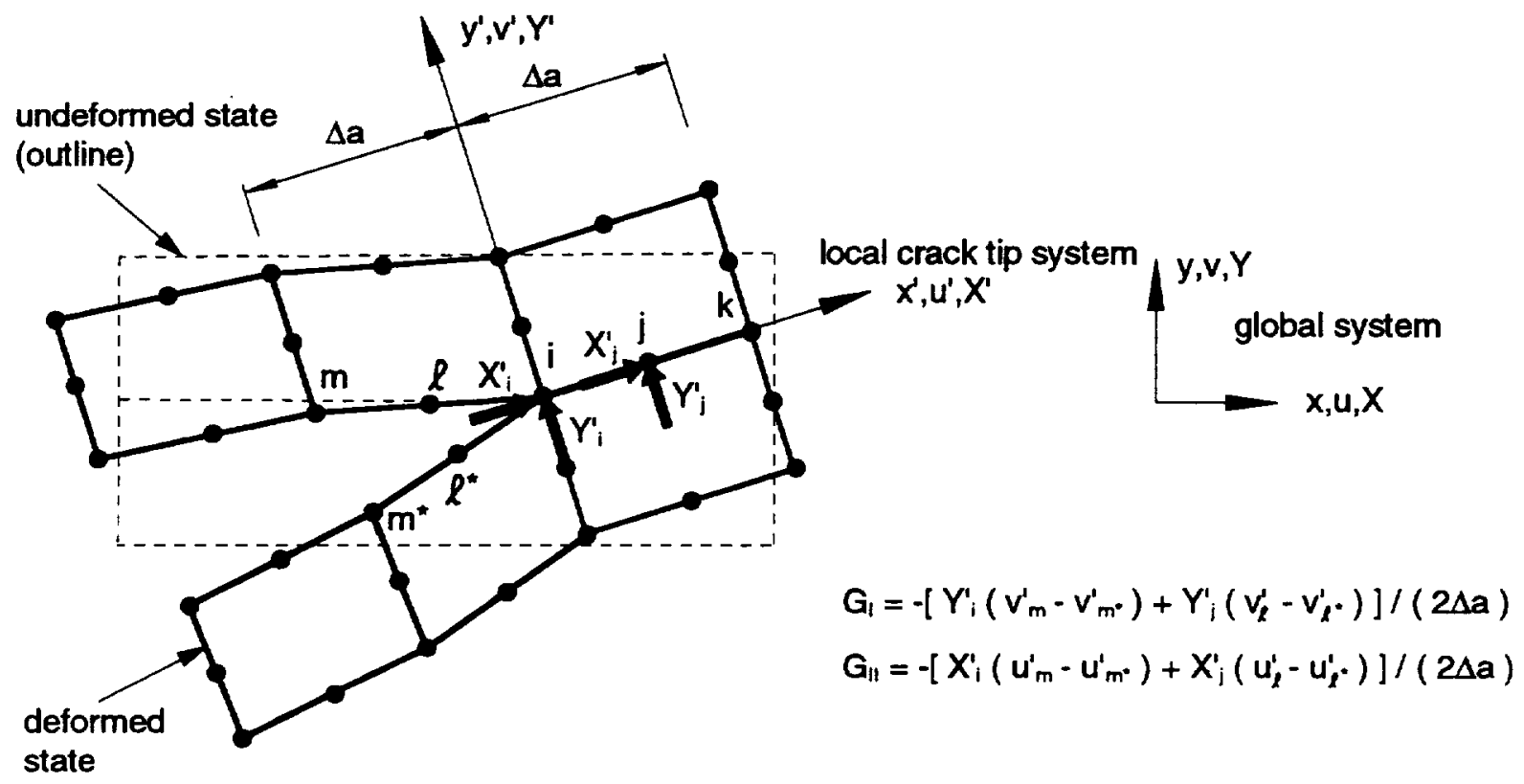

Figure 6. Virtual Crack Closure Technique (VCCT). 


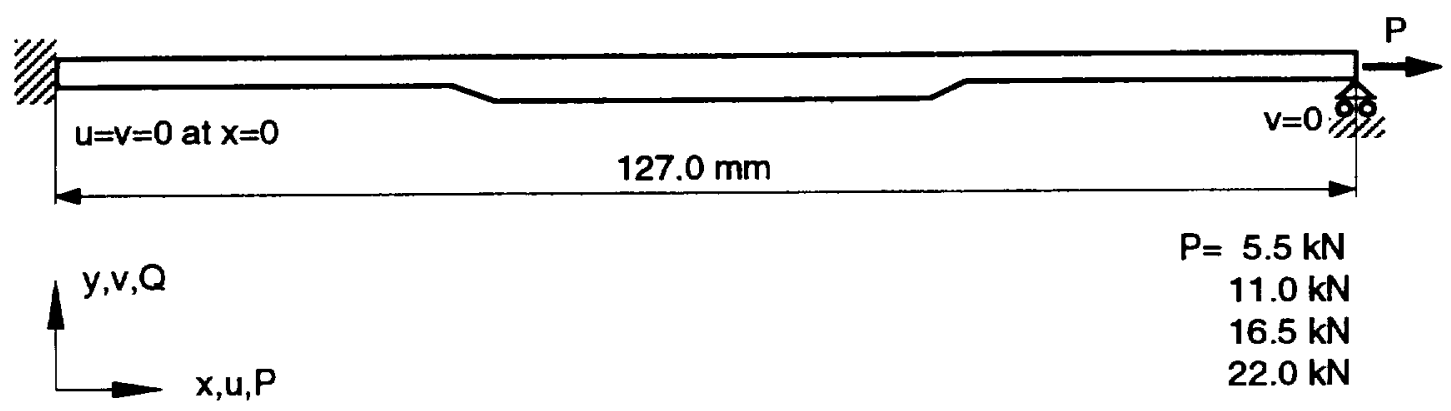

(a) Tension Load Case
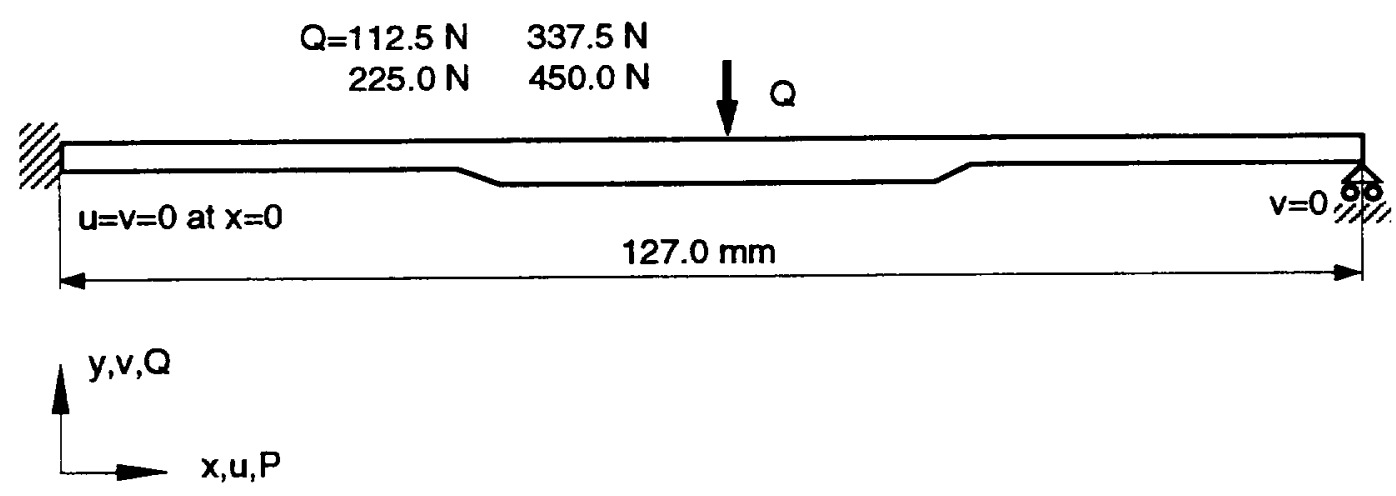

(b) Bending Load Case

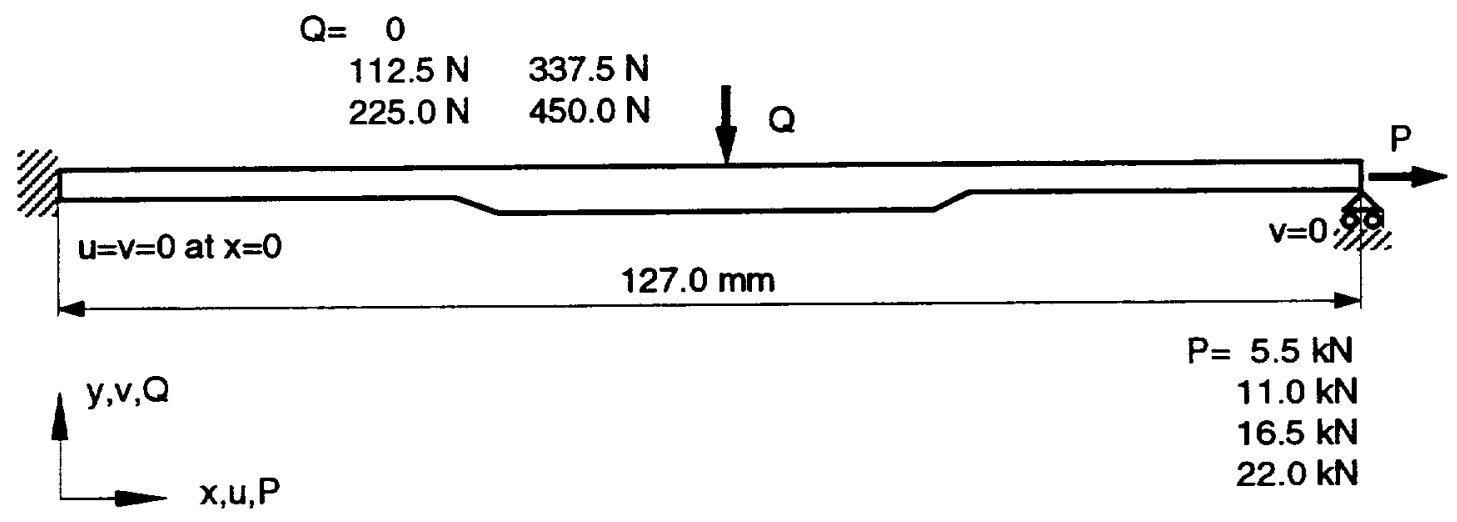

(c) Combined Load Condition

Figure 7. Loads and Boundary Conditions For Tension and ThreePoint Bending and Combined Loading Case. 


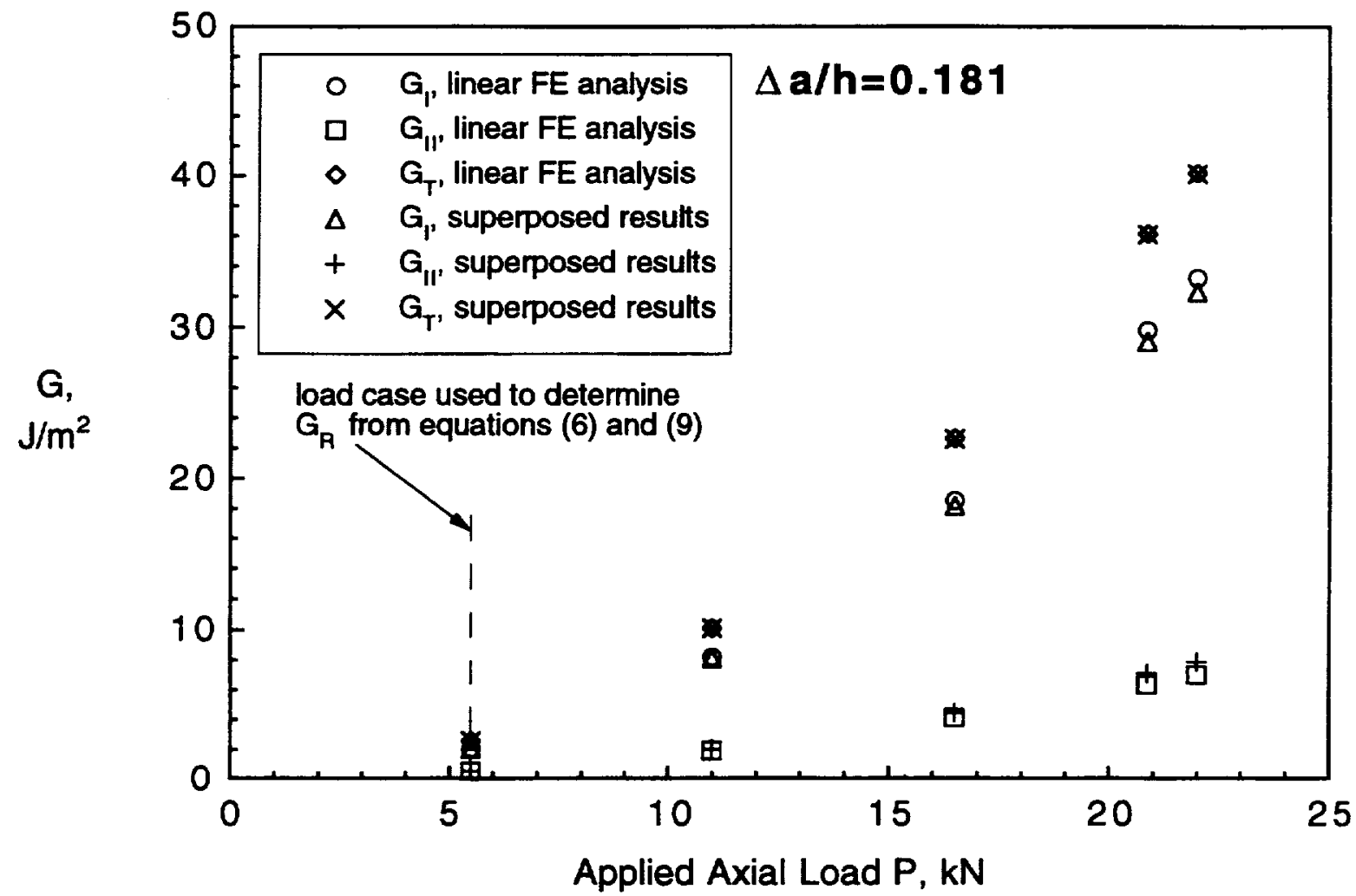

Figure 8. Comparison of Computed Strain Energy Release Rates with Superposed Values for Tension Load Case.

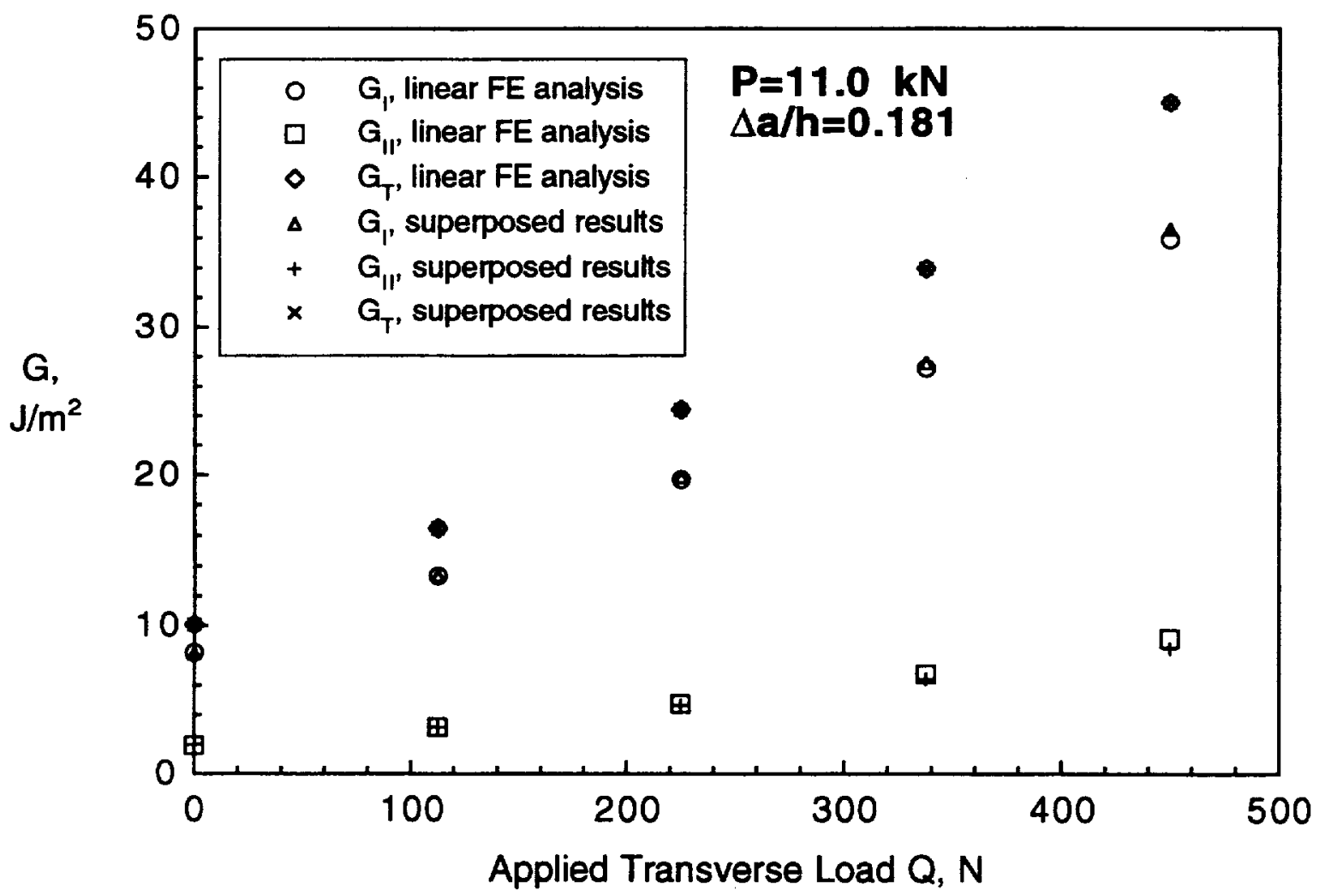

Figure 9. Comparison of Computed Strain Energy Release Rate Components with Superposed Values for Combined Tension and Bending Load Case. 


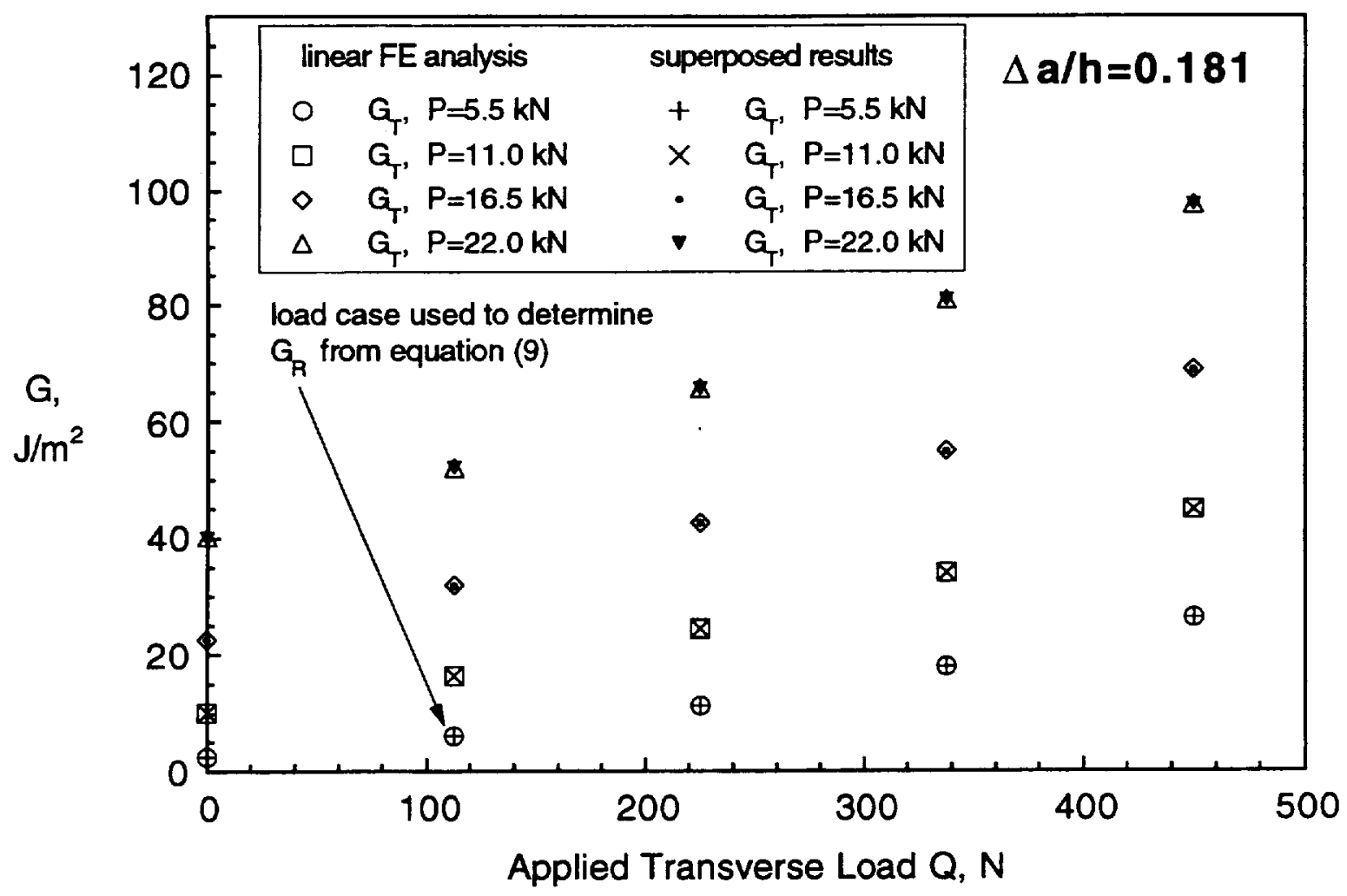

Figure 10. Comparison of Computed Total Strain Energy Release Rates with Superposed Values for Combined Tension and Bending Load Cases.

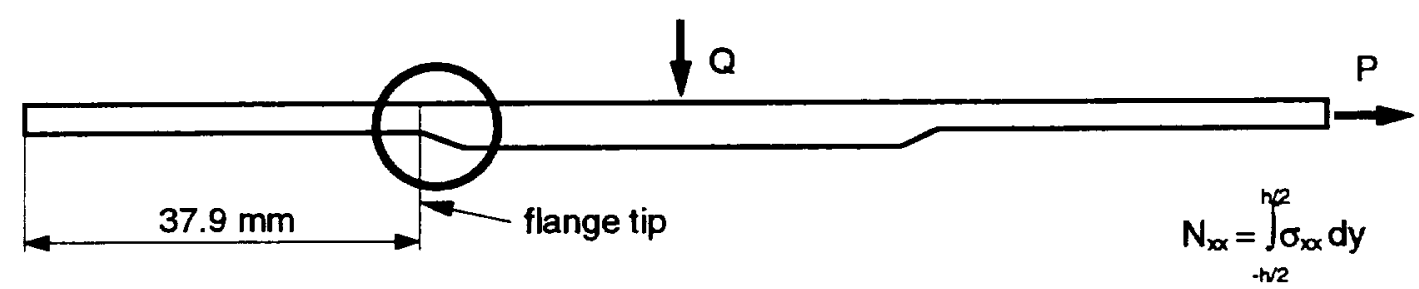

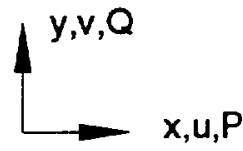

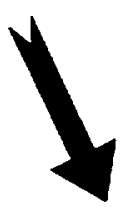

$$
Q_{x y}=\int_{-h / 2}^{n / 2} \tau_{x y} d y
$$$$
M_{x x}=\int_{-w 2}^{w / 2} \sigma_{x \alpha} y d y
$$

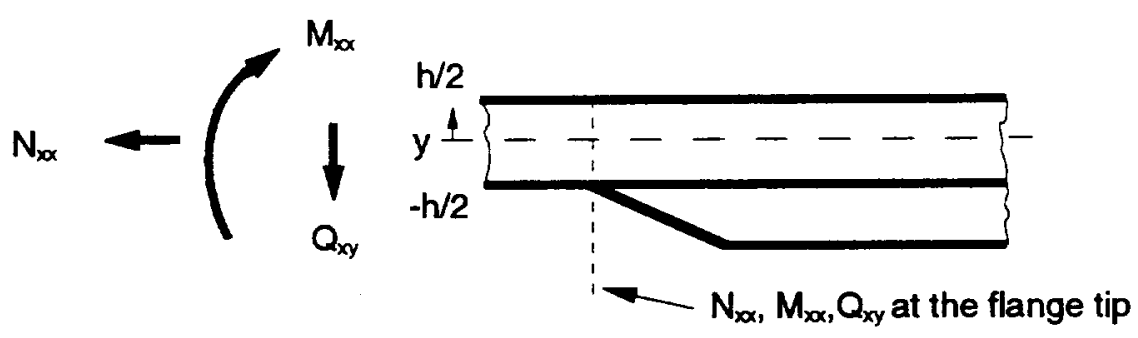

Figure 11. Calculation of Force and Moment Resultants 


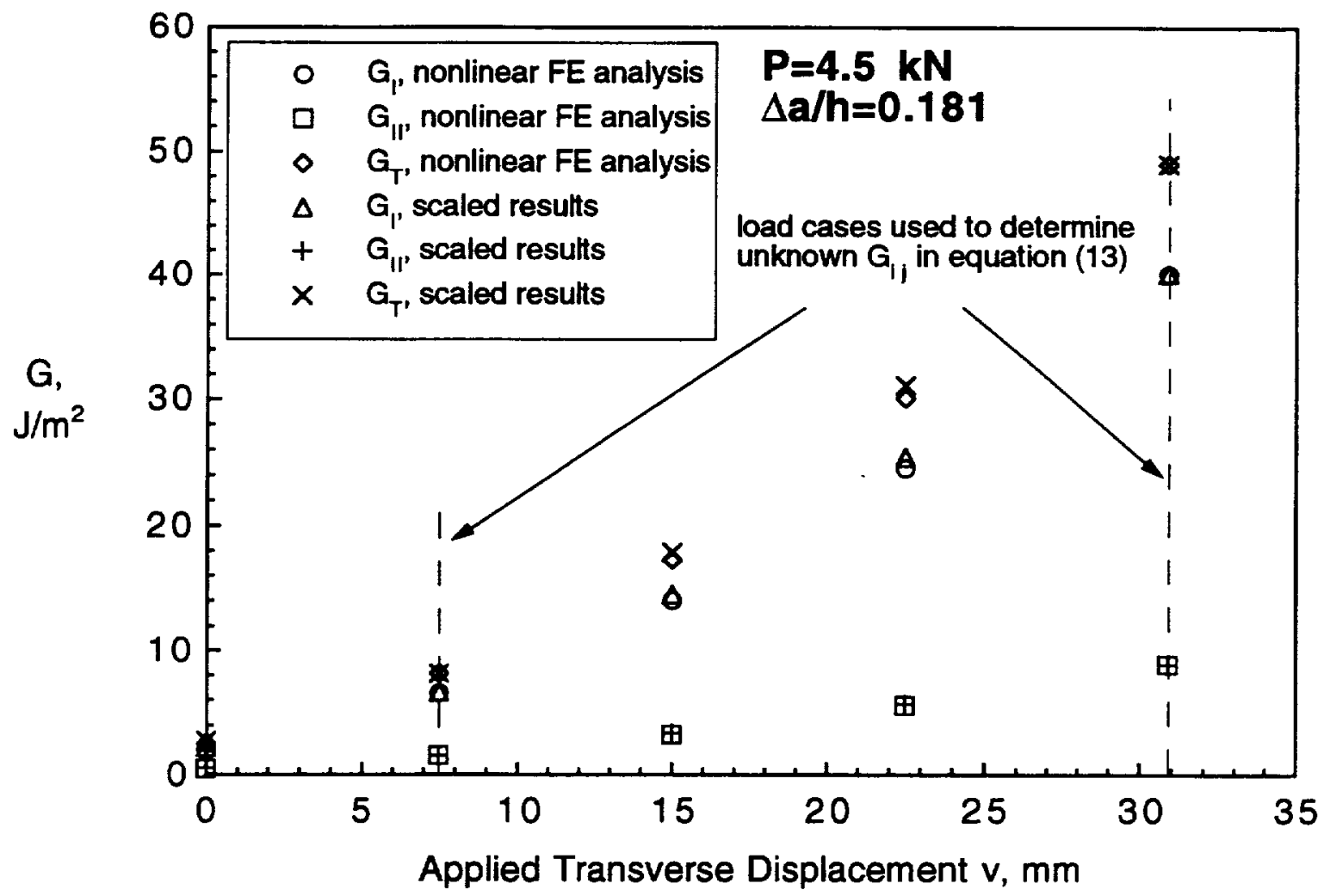

Figure 12. Comparison of Computed Strain Energy Release Rate Components with Scaled Values for Combined Tension and Bending Load Case.

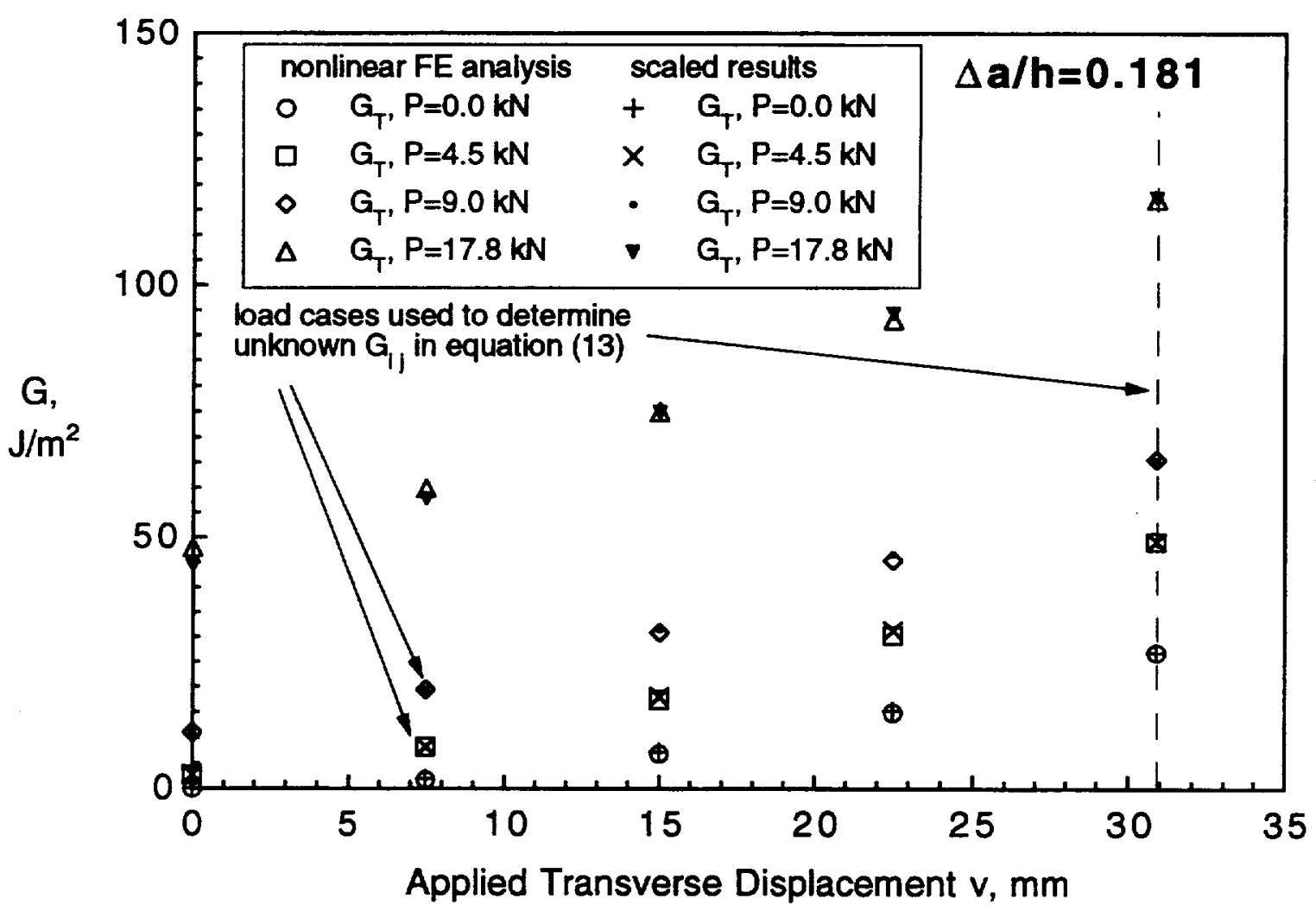

Figure 13. Comparison of Computed Total Strain Energy Release Rates with Scaled Values for Combined Tension and Bending Load Cases. 


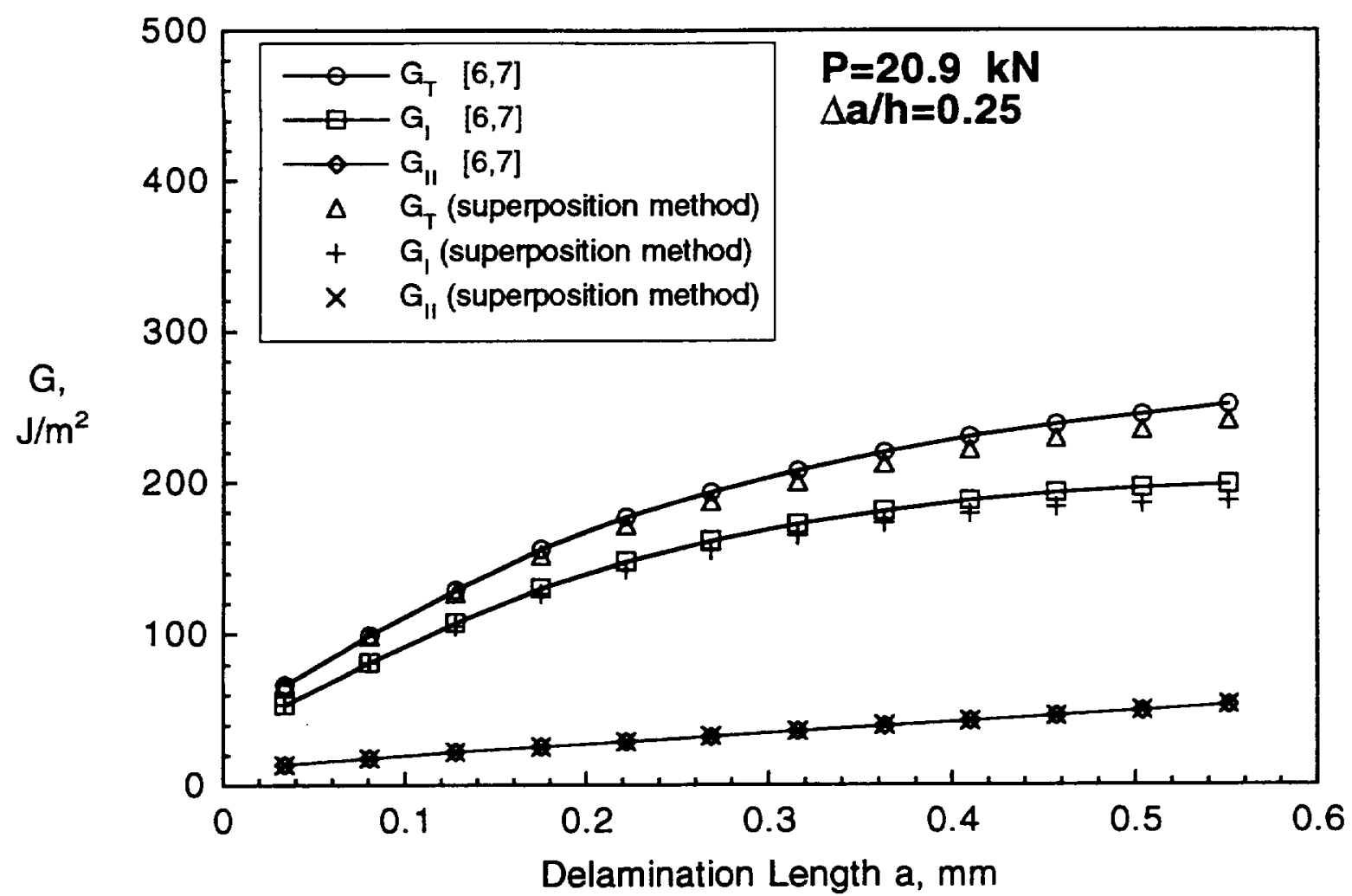

Figure 14. Computed Strain Energy Release Rates for Delamination Growth in a $90^{\circ} / 45^{\circ}$ Flange Ply Interface for Tension Load Case.

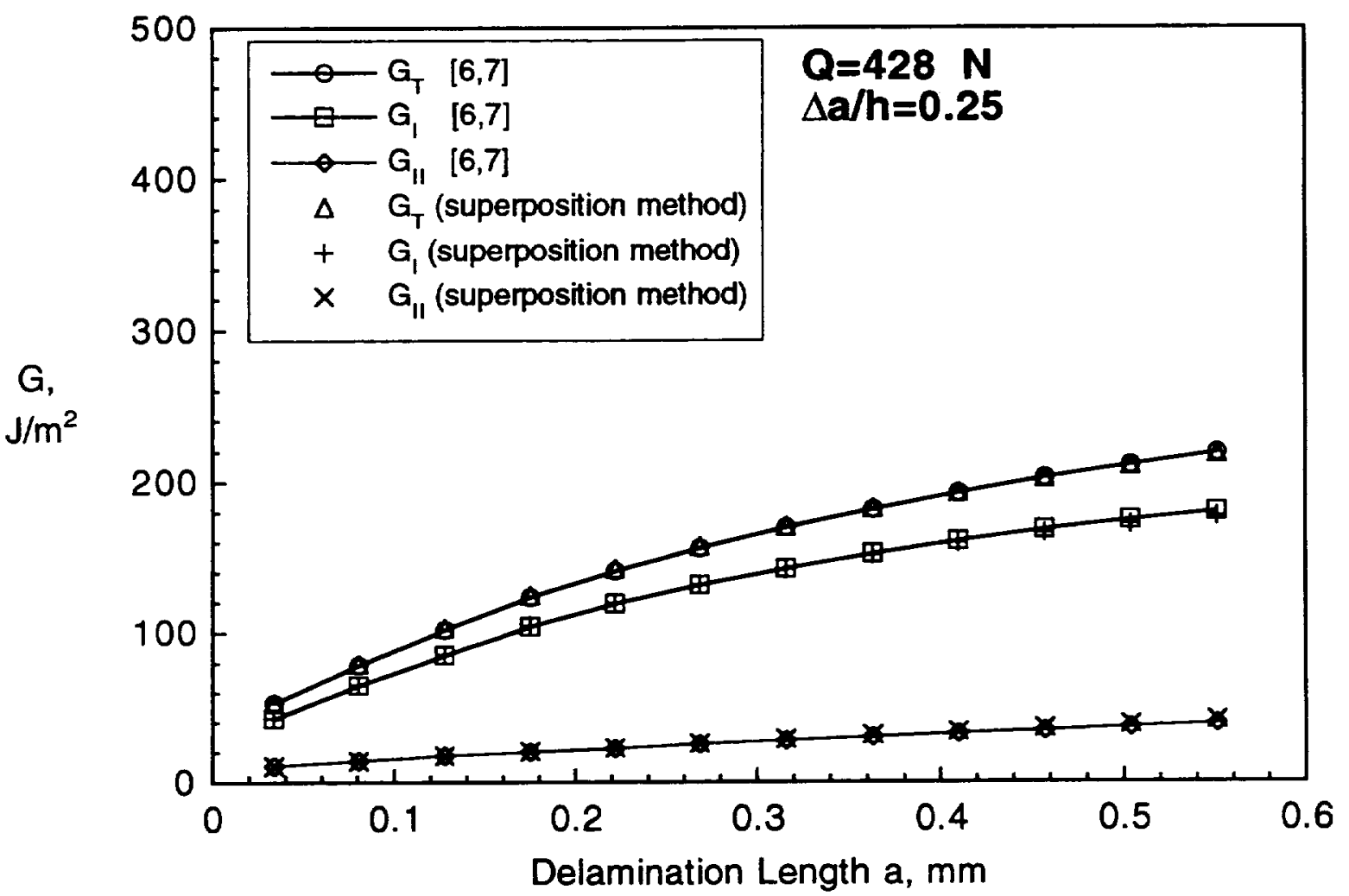

Figure 15. Computed Strain Energy Release Rates for Delamination Growth in a $90^{\circ} / 45^{\circ}$ Flange Ply Interface for Three-Point Bending Load Case. 


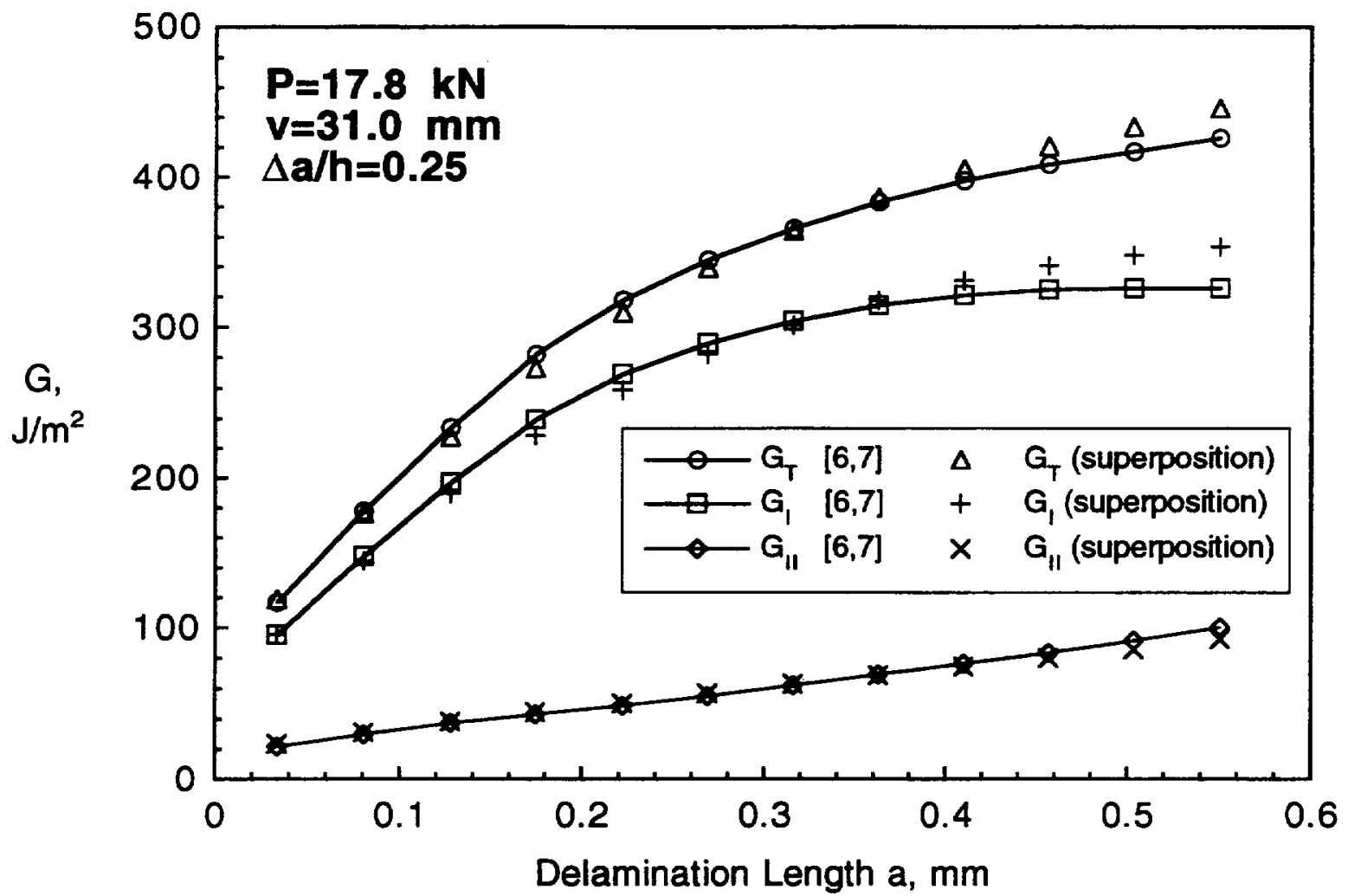

Figure 16. Computed Strain Energy Release Rates for Delamination Growth in a $90^{\circ} / 45^{\circ}$ Flange Ply Interface for Combined Tension and Bending Load Case.

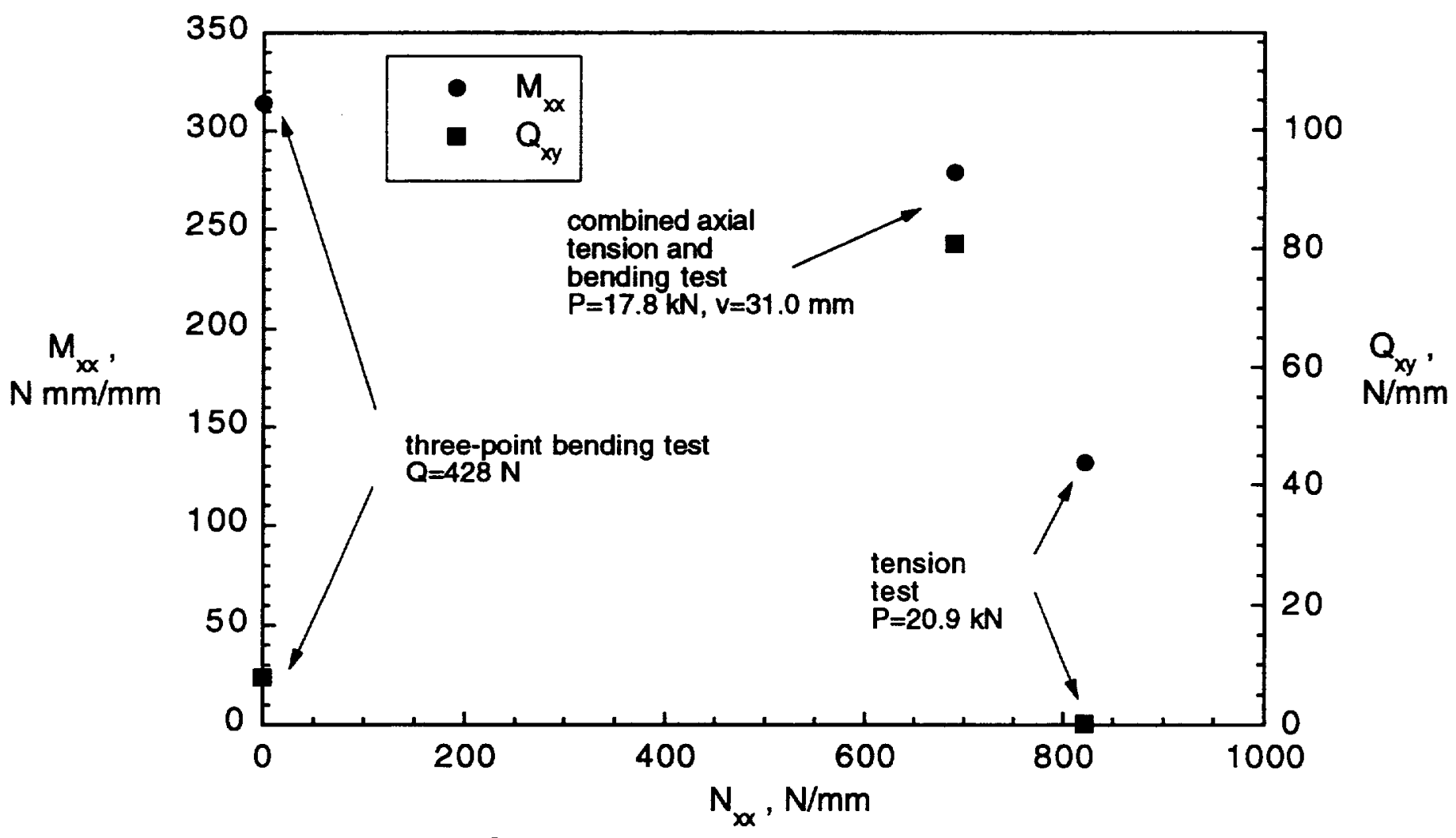

Figure 17. Computed Force and Moment Resultants at Flange Tip. 

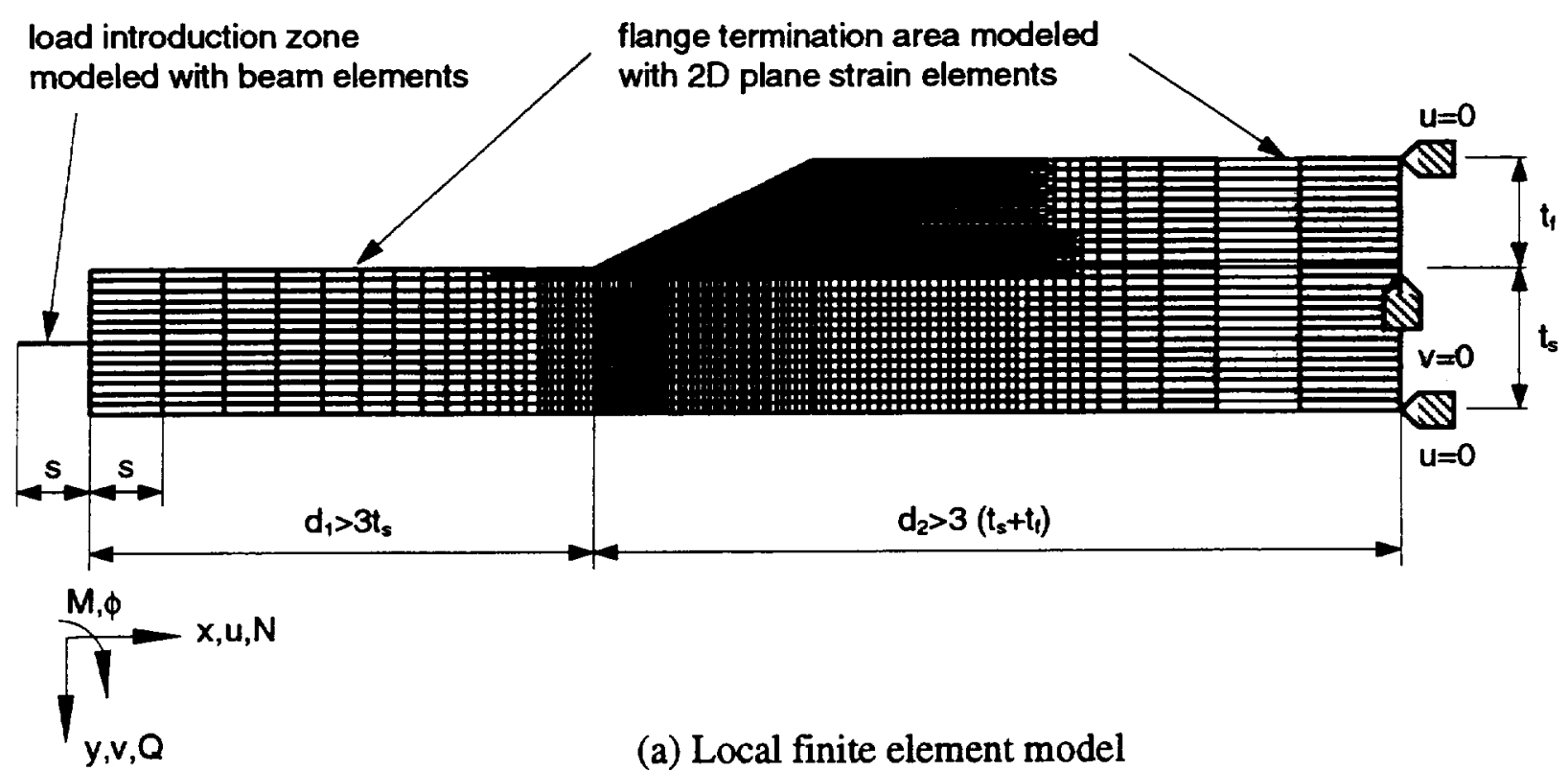

(a) Local finite element model

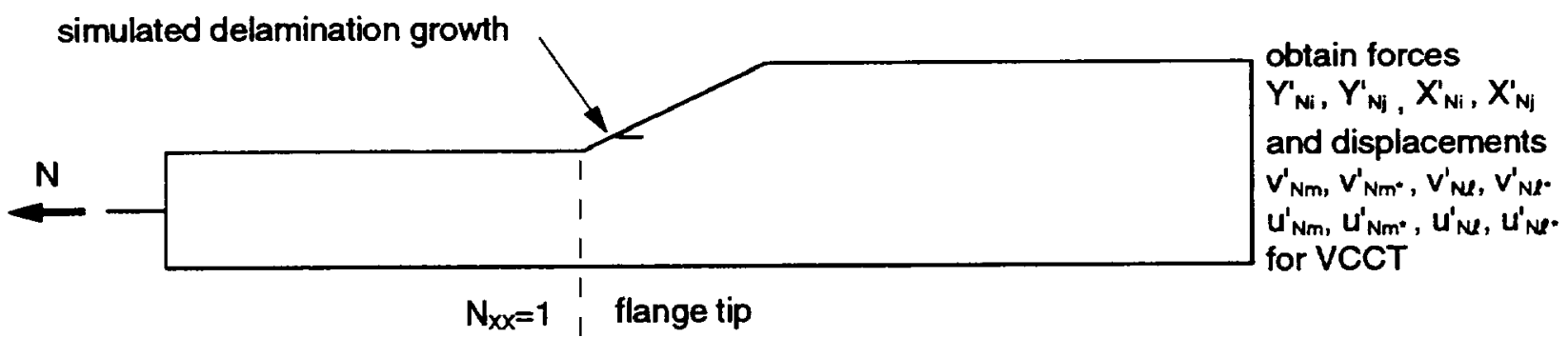

(b) Unit axial tension load case

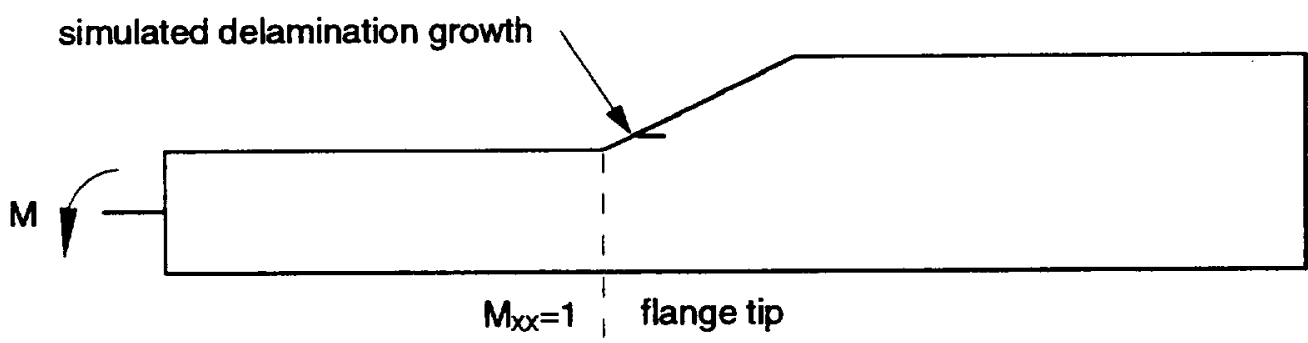

obtain forces $Y_{M i}, Y_{M j}^{\prime}, X_{M i}^{\prime}, X_{M i}^{\prime}$ and displacements $v_{M m_{1}}^{\prime} v_{M^{*}}^{\prime}, v_{M P}^{\prime}, v_{M L^{*}}^{\prime}$ $u_{M m}^{\prime}, u_{M n^{*}}^{\prime}, u_{M 2}^{\prime}, u_{M M^{*}}^{\prime}$ for VCCT

(c) Unit bending moment load case

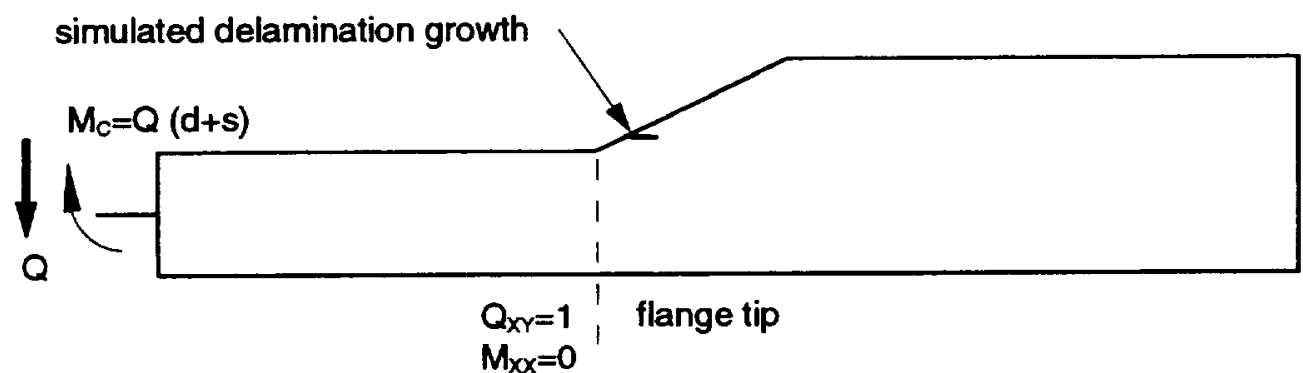

obtain forces $Y_{\mathrm{Oi}_{1},} Y_{\mathrm{aj}}, \mathrm{X}_{\mathrm{ai}}, \mathrm{X}_{\mathrm{aj}}$ and displacements $v_{\alpha m}^{\prime}, v_{O m^{*}}^{\prime}, v_{\alpha \mu}^{\prime}, v_{\alpha \rho}^{\prime}$.

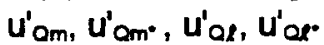
for VCCT

(d) Unit tranverse shear load case

Figure 18. Local finite element model for linear analyses and unit loads. 


\begin{tabular}{|c|c|c|c|c|}
\hline \multicolumn{3}{|c|}{ REPORT DOCUMENTATION PAGE } & & \\
\hline \multicolumn{5}{|c|}{ 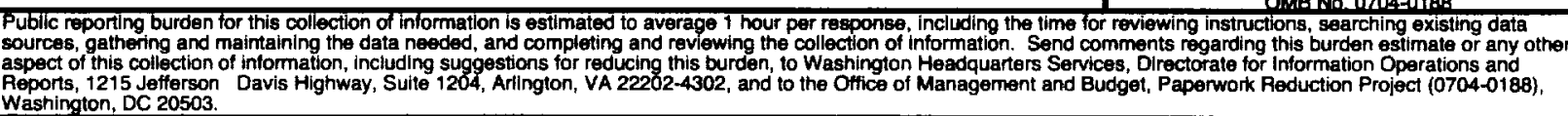 } \\
\hline 1. AGENCY USE ONLY (Leave blank) & $\begin{array}{l}\text { 2. REPORT DATE } \\
\text { July } 1999\end{array}$ & \multicolumn{3}{|c|}{$\begin{array}{l}\text { 3. REPORT TYPE AND DATES COVERED } \\
\text { Technical Memorandum }\end{array}$} \\
\hline \multicolumn{3}{|c|}{$\begin{array}{l}\text { 4. TITLE AND SUBTTLE } \\
\text { A Method for Calculating Strain Energy Release Rates in Preliminary } \\
\text { Design of Composite Skin/Stringer Debonding Under Multi-Axial Loading }\end{array}$} & \multirow{2}{*}{\multicolumn{2}{|c|}{$\begin{array}{l}\text { 5. FUNDING NUMBERS } \\
\text { WU 581-10-21-01 }\end{array}$}} \\
\hline \multicolumn{3}{|c|}{$\begin{array}{l}\text { 6. AUTHOA(S) } \\
\text { Ronald Krueger, Pierre J. Minguet and T. Kevin O'Brien }\end{array}$} & & \\
\hline \multicolumn{3}{|c|}{ 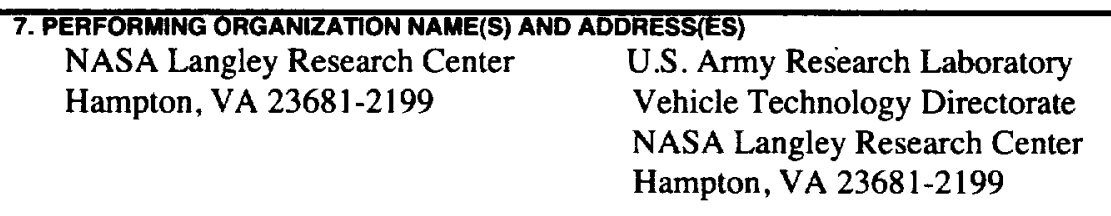 } & \multicolumn{2}{|c|}{$\begin{array}{l}\text { 8. PERFOAMING ORGANIZATION } \\
\text { REPORT NUMBER }\end{array}$} \\
\hline \multicolumn{3}{|c|}{$\begin{array}{l}\text { 9. SPONSOAINGMONITOAING AGENCY NANE(S) AND ADDRESS(ES) } \\
\text { National Aeronautics and Space Administration } \\
\text { Washington, DC 20546-0001 } \\
\text { and } \\
\text { U.S. Army Research Laboratory } \\
\text { Adelphi, MD 20783-1145 }\end{array}$} & \multicolumn{2}{|c|}{$\begin{array}{l}\text { 10. SPONSOFINGMONTOMIMG } \\
\text { AGENCY REPOAT NUMAER } \\
\text { NASA/TM-1999-209365 } \\
\text { ARL-TR-2012 }\end{array}$} \\
\hline \multicolumn{5}{|c|}{$\begin{array}{l}\text { 11. SUPPLEMENTARY NOTES } \\
\text { Krueger: National Research Council Research Associate, Langley Research Center; Minguet: The Boeing } \\
\text { Company, Philadelphia, PA 19142. Paper presented at the ASTM Symposium on Composites Structures: } \\
\text { Theory and Practice, May } 17-18,1999 \text {, in Seattle, WA. }\end{array}$} \\
\hline \multicolumn{3}{|c|}{$\begin{array}{l}\text { 12a. DISTRIBUTIONAVALABILTY STATEMENT } \\
\text { Unclassified-Unlimited } \\
\begin{array}{ll}\text { Subject Category } 24 & \text { Distribution: Standard } \\
\text { Availability: NASA CASI (301) } 621-0390 & \end{array}\end{array}$} & \multicolumn{2}{|c|}{ 12b. DISTRIBUTION CODE } \\
\hline \multicolumn{5}{|c|}{$\begin{array}{l}\text { 13. ABSTAACT (Maximum } 200 \text { words) } \\
\text { Three procedures were developed to determine strain energy release rates in composite skin/stringer specimens } \\
\text { for various loading conditions. These procedures may be used for parametric studies in such a way that only a } \\
\text { few finite element computations will be necessary for a study of many load combinations. The results were } \\
\text { compared with mixed mode energy release rates calculated directly from nonlinear two-dimensional plane-strain } \\
\text { finite element analyses using the virtual crack closure technique. The first procedure involved solving three } \\
\text { unknown parameters needed to determine the energy release rates. This technique was only applicable if the } \\
\text { structure exhibits a linear behavior. A second technique was derived which was applicable in the case of } \\
\text { nonlinear behavior. The technique involved calculating six unknown parameters from a set of six simultaneous } \\
\text { linear equations and was not time efficient. A third procedure was developed to calculate mixed mode energy } \\
\text { release rates as a function of delamination lengths. Only one nonlinear finite element analysis of the specimen is } \\
\text { required to obtain a reference solution. The delamination was extended in separate sub-models to obtain the } \\
\text { distribution of } G \text { with delamination lengths. Although additional modeling effort is required to create the sub- } \\
\text { models, this local technique is efficient for parametric studies. }\end{array}$} \\
\hline \multirow{2}{*}{\multicolumn{4}{|c|}{$\begin{array}{l}\text { 14. SUBJECT TERMS } \\
\text { Composite materials; Fracture mechanics; Energy release rate; Finite element } \\
\text { analysis; Virtual crack closure technique; Skin/flange interface }\end{array}$}} & $\begin{array}{l}\text { 15. NUMBER OF PAGES } \\
38\end{array}$ \\
\hline & & & & $\begin{array}{l}\text { 16. PRICE CODE } \\
\text { A03 }\end{array}$ \\
\hline $\begin{array}{l}\text { 17. SECURITY CLASSIFICATION } \\
\text { OF REPORT } \\
\text { Unclassified }\end{array}$ & $\begin{array}{l}\text { 18.SEGUAIVYCLASSTFICATION } \\
\text { OF THIS PAGE } \\
\text { Unclassified }\end{array}$ & $\begin{array}{l}\text { 19.SECUAFIIYCLLSSIF } \\
\text { OF ABSTRACT } \\
\text { Unclassified }\end{array}$ & AIION & $\begin{array}{l}\text { 20. पIIIMATION } \\
\text { OF ABSTACT } \\
\text { UL }\end{array}$ \\
\hline
\end{tabular}


. 
